Research article

\title{
Hot melt extruded polysaccharide blends for controlled drug delivery
}

Y. Benzine ${ }^{1}$, F. Siepmann ${ }^{1}$, C. Neut ${ }^{2}$, F. Danede ${ }^{3}$, J.F. Willart ${ }^{3}$, J. Siepmann ${ }^{1, *}$, Y. Karrout ${ }^{1, * *}$

${ }^{1}$ Univ. Lille, Inserm, CHU Lille, U1008, F-59000 Lille, France

${ }^{2}$ Univ. Lille, Inserm, CHU Lille, U995- LIRIC, F-59000 Lille, France

${ }^{3}$ Univ. Lille, USTL UMET UMR CNRS 8207, F-59650 Villeneuve d'Ascq, France

*correspondence:

Prof. Juergen Siepmann

College of Pharmacy, INSERM U1008

University of Lille

3 rue du Professeur Laguesse

59006 Lille, France

juergen.siepmann@univ-lille.fr

** correspondence:

Dr. Youness Karrout

College of Pharmacy, INSERM U1008

University of Lille

3 rue du Professeur Laguesse

59006 Lille, France

youness.karrout@univ-lille.fr 


\section{Abstract}

Different types of hot melt extrudates were prepared based on a variety of blends of ethylcellulose with a $2^{\text {nd }}$ polysaccharide, namely hydroxypropyl methylcellulose (HPMC), pectin, maize starch, inulin, maltodextrin, guar gum, and chitosan. In selected cases, the polymer:polymer blend ratio was varied from 80:20, 70:30, 60:40, 50:50, 40:60, 30:70 to 20:80. The addition of appropriate amounts of plasticizers allowed reducing the extrusion temperature to about $100{ }^{\circ} \mathrm{C}$. The impacts of the screw speed, extrusion temperature, amount and type of plasticizer as well as of the amount and type of drug (10 to $60 \%$ theophylline or diprophylline) were studied. Drug release was measured in $0.1 \mathrm{M} \mathrm{HCl}$ for $2 \mathrm{~h}$, followed by phosphate buffer pH 6.8 and (optionally) fecal samples to simulate the colon (under anaerobic conditions). DSC measurements and optical microscopy were used to characterize the physical state and morphology of the systems. Interestingly, hot melt extrudates based on ethylcellulose:guar gum blends could be easily prepared at a temperature of $100{ }^{\circ} \mathrm{C}$ and offered large spectra of drug release patterns for both: slightly water-soluble theophylline as well as freely water-soluble diprophylline. About constant drug release rates could be obtained during prolonged periods of time. Importantly, the resulting drug release rates from hot melt extrudates based on ethylcellulose:guar gum 80:20 blends were similar in the presence and absence of colonic bacteria, indicating that the ethylcellulose seems to protect the guar gum from degradation upon exposure to fecal samples. Furthermore, these systems were long term stable for at least 1 year under ambient conditions. Thus, they can offer an interesting potential as oral controlled drug delivery systems.

Keywords: Hot melt extrusion; controlled release; ethylcellulose; guar gum; theophylline. 


\section{Introduction}

Polymer blends offer an interesting potential for controlled drug delivery systems $[1,2,3,4,5,6]$, both as matrix formers $[7,8,9,10]$ and as coating materials $[11,12,13,14,15]$. By simply varying the polymer:polymer blend ratio, the resulting key properties of the systems can be effectively varied, allowing to provide large spectra of possible drug release kinetics $[16,17,18]$. For example, a variety of blends of enteric and non-enteric polymer blends has been used to control the resulting drug release kinetics from coated pellets [19,20]. Importantly, the presence of the non-enteric polymer can effectively hinder the leaching of the enteric polymer out of the film coating at neutral $\mathrm{pH}$ [21]. Thus, one polymer can efficiently "mask" key properties of the other polymer, if the two compounds are intimately mixed [22]. The polymer:polymer blend ratio as well as the manufacturing technique (determining the inner system structure) can strongly affect the efficiency of such "masking” phenomena [23]. Polymer:polymer blends have also been used in a variety of controlled drug delivery systems as matrix formers [24,25,26]. For example, Zhang et al. [27] studied matrix tablets loaded with theophylline based on blends of polyethylene oxide and Carbopol 907 at different $\mathrm{pH}$ values. The resulting drug release kinetics were found to be affected by the $\mathrm{pH}$-dependent interactions between the two polymers. Also, Hamoudi-Ben Yelles et al. [28] added small amounts of hydrophilic polymers (Poloxamer 188 and polyethylene oxide $200 \mathrm{kDa}$ ) to poly(lactic-co-glycolic acid) (PLGA)-based implants to alter drug release and the importance of autocatalytic effects. Furthermore, polymer:polymer blends have been proposed as matrix formers in hot melt extrudates for controlled drug delivery. For instance, Verhoeven et al. [29] prepared mini-matrices by hot melt extrusion of ethylcellulose blended with polyethylene glycol/polyethylene oxide to provide a variety of metoprolol tartrate release kinetics.

The type of polymers used, the polymer blend ratio as well as the manufacturing conditions determine the resulting system properties and, thus, the control of drug release. 
The basic principle is that the drug is "trapped" within the polymeric system and different types of mass transport phenomena can be involved in the control of drug release, such as water diffusion into the system, drug dissolution and diffusion, polymer swelling and dissolution, osmotic effects, polymer degradation and pore formation upon leaching of watersoluble compounds into the surrounding bulk fluid (to mention just a few). In the case of polymer blends, the properties of both compounds might be decisive, or one of them might dominate. For example, when blending a polymer that is permeable for many drugs with a polymer that is poorly permeable, broad spectra of drug release patterns might be obtained by simply varying the polymer:polymer blend ratio [30]. Also differences in drug solubility or drug loading might be compensated by adjusting the polymer:polymer blend ratio. For example, high loadings of a freely water-soluble drug in a matrix system generally lead to fast drug release. This might be compensated by increasing the portion of the poorly permeable polymer in the dosage form. Also, one polymer might assure the mechanical stability of the drug delivery system within the gastrointestinal tract, whereas the other polymer might trigger drug release in specific segments (e.g. small intestine or colon) [31,32,33,34,35,36]. Furthermore, the solubilities of the two polymers might be complementary: For example, ethylcellulose:guar gum blends have been proposed as film coating materials to provide controlled drug release that is not susceptible to the co-consumption of alcoholic beverages $[37,38,39]$. The basic idea is that ethylcellulose is not soluble in water, but in ethanol. Viceversa, guar gum is soluble in water, but not in ethanol. Appropriate ethylcellulose:guar gum blends were shown to be able to release theophylline from coated pellets with release rates that were very similar in release media containing 0,20 or $40 \%$ ethanol.

The aim of this study was to explore the potential of blends of ethylcellulose with a second polysaccharide as matrix former in controlled release hot melt extrudates. Ethylcellulose was chosen to provide good mechanical stability of the systems. But it is known to be poorly permeable for many drugs [40]. Thus, it was combined with different 
types and amounts of a more permeable second polysaccharide, namely hydroxypropyl methylcellulose (HPMC), pectin, maize starch, inulin, maltodextrin, guar gum, and chitosan. Optionally, different types and amounts of plasticizers (dibutyl sebacate, triethyl citrate and polyethylene glycol) were added. Theophylline was selected as model drug exhibiting slight water solubility, diprophylline as freely water-soluble model drug. The drug loading was varied from 10 to $60 \%$. The key manufacturing parameters (temperature and screw speed) as well as the polymer:polymer blend ratio were varied. Drug release was measured under conditions simulating the contents of the upper gastro intestinal tract $(0.1 \mathrm{M} \mathrm{HCl}$ and phosphate buffer $\mathrm{pH}$ 6.8), as well as the colon (upon exposure to human fecal samples).

\section{Materials and methods}

\subsection{Materials}

Ethylcellulose (EC, Ethocel Standard 10 premium; Colorcon, Massy, France); hydroxypropyl methylcellulose (HPMC, Methocel E5 Premium LV; Colorcon, Kent, England); pectin and maltodextrin (UniPectin and $\mathrm{C}^{*}$ Actistar 11700 Tapioca maltodextrin, Cargill, Krefeld, Germany); maize starch (C*PharmGel 03406; Cargill, Gent, Belgium); guar gum (viscosity of a $1 \%$ solution in water at $25^{\circ} \mathrm{C}$ : $\sim 5000 \mathrm{cP}$; Cooper, Melun, France); inulin (Inulin HPX; Beneo, Oreye, Belgium); chitosan (Crab Shell chitosan, Mw = 800 kDa, degree of deacetylation $=80-90 \%$; Bio 21, Chonburi, Thailand); triethyl citrate (TEC; Alfa Aesar, Karlsruhe, Germany); polyethylene glycol (PEG 1500; Pluracare E 1500 Flasks; BASF, Ludwigshafen, Germany); dibutyl sebacate (DBS; Stearinerie Dubois, Boulogne-Billancourt, France); anhydrous theophylline and diprophylline (BASF, Ludwigshafen, Germany); extracts from beef and tryptone (Pancreatic digest of casein; Becton Dickinson, Sparks, USA); yeast extract (Oxoid, Hants, UK); sodium chloride (J. T. Baker, Deventer, 
Netherlands); L-cysteine hydrochloride hydrate (Acros Organics, Geel, Belgium); Ringer solution (Merck, Darmstadt, Germany); acetic acid glacial (Fisher Bioblock, Illkirch, France); acetonitrile (CWR, Fontenay-sous-Bois, France); sodium acetate (Sodium acetate anhydrous, $99 \%$, ThermoFisher, Kandel, Germany)

\subsection{Preparation of hot melt extrudates}

Drug and polymer powders were blended for $10 \mathrm{~min}$ at $98 \mathrm{rpm}$ in a Turbula T2A (Willy A. Bachofen Maschinenfabrik, Muttenz, Switzerland), followed by manual mixing in a mortar with a plasticizer (TEC, DBS or PEG 1500). The compositions were varied as indicated. Polymer:polymer blend ratios are expressed in weight:weight, plasticizer percentages are referring to the mass of ethylcellulose (mass of ethylcellulose $=100 \%$ ), drug percentages refer to the total mass of the hot melt extrudates (mass of extrudate $=100 \%$ ). The plasticized blends were kept at room temperature for $24 \mathrm{~h}$, followed by extrusion with a Nano 16 twin screw extruder (Leistritz, Nuremberg, Germany), equipped with a $4 \mathrm{~mm}$ diameter die (screw diameter $=16 \mathrm{~mm}$, length $/$ diameter ratio $=26.25)$. Figure S1 shows the setting of the screw elements. The process temperatures were kept constant at $170-170-170-170{ }^{\circ} \mathrm{C}$ or $100-$ $100-100-100{ }^{\circ} \mathrm{C}$ [zone 4 (die) - zone 3 - zone 2 - zone 1 ], as indicated. The feed rate was set at $3 \mathrm{~mL} / \mathrm{min}$. After cooling, the hot melt extrudates were manually cut into cylinders.

\subsection{Optical microscopy}

Macroscopic pictures of hot melt extrudates were taken with an optical image analysis system (Nikon SMZ-U; Nikon, Tokyo, Japan), equipped with a Zeiss camera (Axiocam ICc1; Zeiss, Jena, Germany). Cross-sections of hot melt extrudates were obtained by manual breaking. 


\subsection{In-vitro drug release}

Under conditions simulating the upper gastro intestinal tract: Hot melt extrudates were placed into flasks (1 sample per flask), filled with $200 \mathrm{~mL} 0.1 \mathrm{M} \mathrm{HCl}$ and agitated at $80 \mathrm{rpm}$ (in a horizontal shaker, $37{ }^{\circ} \mathrm{C}$; GFL 3033, Gesellschaft fuer Labortechnik, Burgwedel, Germany). After $2 \mathrm{~h}$, the release medium was completely exchanged with phosphate buffer pH 6.8 (USP 41). At pre-determined time points, $3 \mathrm{~mL}$ samples were withdrawn and analyzed UV-spectrophotometrically (UV-1800; Shimadzu, Kyoto, Japan) at $\lambda=275 \mathrm{~nm}$ (theophylline) or $\lambda=274 \mathrm{~nm}$ (diprophylline) for their drug content.

Under conditions simulating the entire gastro intestinal tract: Hot melt extrudates were exposed to $0.1 \mathrm{M} \mathrm{HCl}$ for $2 \mathrm{~h}$ and subsequently to phosphate buffer $\mathrm{pH} 6.8$ (USP 41) for $6 \mathrm{~h}$, in a USP Apparatus $3\left(20 \mathrm{dpm}, 37^{\circ} \mathrm{C}\right.$, Bio-Dis; Varian, Paris, France). Afterwards, the extrudates were transferred into $120 \mathrm{~mL}$ flasks filled with: (i) $100 \mathrm{~mL}$ culture medium inoculated with human fecal samples, or (ii) culture medium free of feces for reasons of comparison. The samples were agitated (50 rpm; Stuart, Cole-Parmer; Villepinte, France) at $37{ }^{\circ} \mathrm{C}$ under anaerobic conditions (AnaeroGen 2.5 L; Thermo Scientific; Illkirch, France). Culture medium was prepared by dissolving $1.5 \mathrm{~g}$ beef extract, $3 \mathrm{~g}$ yeast extract, $5 \mathrm{~g}$ tryptone, $2.5 \mathrm{~g} \mathrm{NaCl}$ and $0.3 \mathrm{~g} \mathrm{~L}$-cysteine hydrochloride hydrate in $1 \mathrm{~L}$ distilled water $(\mathrm{pH} 7.0 \pm 0.2)$ and subsequent sterilization in an autoclave. Culture medium inoculated with fecal samples was prepared as follows: Human fecal samples (approximately $1 \mathrm{~g}$ ) were diluted 1:200 with cysteinated Ringer solution; $2.5 \mathrm{~mL}$ of this suspension was diluted with culture medium to $100 \mathrm{~mL}$. At pre-determined time points, $2 \mathrm{~mL}$ samples were withdrawn, centrifuged at $10000 \mathrm{rpm}$ for $10 \mathrm{~min}$ (Centrifuge Universal 320; Hettich, Tuttlingen, Germany), filtered (0.45 $\mu \mathrm{m}$, Millex-HU; Merck Millipore, Tullagreen, Ireland) and analyzed by HPLC for their drug content using a Thermo Fisher Scientific Ultimate 3000, equipped with a LPG 3400 SD/RS pump, an auto sampler (WPS-3000 SL) and a UV-Vis detector (VWD-3400RS) (Thermo Fisher Scientific, Waltham, USA). In the case of theophylline, the mobile phase 
consisted of $10 \%$ acetonitrile and $90 \%$ water (v/v). Samples were injected into a C18 column (Kinetex $5 \mu$ m EVO C18 $100 \AA \AA, 250$ mm x 4.6 mm; Phenomenex, Le Pecq, France) and the flow rate was set at $1.0 \mathrm{~mL} / \mathrm{min}$. The drug was detected UV-spectrophotometrically at $\lambda=275$ $\mathrm{nm}$. In the case of diprophylline, the mobile phase consisted of $35 \%$ acetonitrile and $65 \%$ $0.01 \mathrm{M}$ aqueous sodium acetate solution (v/v). Samples were injected into a Polar C18 column (Luna Omega 3 um Polar C18 100 Å, 150 mm x 4.6 mm; Phenomenex, Le Pecq, France) and the flow rate was set at $1.0 \mathrm{~mL} / \mathrm{min}$. The drug was detected UVspectrophotometrically at $\lambda=274 \mathrm{~nm}$.

\subsection{Differential scanning calorimetry (DSC)}

DSC thermograms were recorded with a Q200 calorimeter (TA Instruments, Guyancourt, France). During all measurements the calorimeter head was flushed with highly pure nitrogen gas. Temperature and enthalpy readings were calibrated using pure indium at the same scan rates as used in the experiments. The samples were placed in hermetic high volume pans, resistant to pressure. Approximately $6 \mathrm{mg}$ samples were heated from - 40 to $300{ }^{\circ} \mathrm{C}$ at $10{ }^{\circ} \mathrm{C} / \mathrm{min}$.

\subsection{Powder X-ray diffraction (PXRD)}

PXRD experiments were conducted with a PanAlytical X'PERT PRO MPD diffractometer $(\lambda \mathrm{CuK} \alpha=1.5418 \AA$ for combined $\mathrm{K} \alpha 1$ and $\mathrm{K} \alpha 2)$, equipped with an $\mathrm{X}$ 'celerator detector (Almlo, The Netherlands). Samples were placed into Lindemann glass capillaries (diameter $=$ $0.7 \mathrm{~mm}$ ) and installed on a rotating sample holder to avoid artifacts due to preferential orientations of crystallites. Heating experiments have been performed in situ, at $10{ }^{\circ} \mathrm{C} / \mathrm{min}$, using the furnace HTC 9634 from Huber (Rimsting, Germany). 


\subsection{Thermogravimetric analysis (TGA)}

TGA experiments were conducted with a Q500 TGA from TA Instruments (Guyancourt, France). Samples were placed in open aluminum pans, and the furnace was flushed with highly pure nitrogen gas $(50 \mathrm{~mL} / \mathrm{min})$. The temperature reading was calibrated using the Curie points of alumel and nickel, while the mass reading was calibrated using balance tare weights provided by TA Instruments. All scans were performed at $10^{\circ} \mathrm{C} / \mathrm{min}$.

\section{Results and discussion}

\subsection{Impact of the type of polymer blend and plasticizer addition}

Figure 1 shows optical macroscopy pictures of hot melt extrudates based on different types of polymer:polymer blends: Ethylcellulose was blended with a selection of other polysaccharides, as indicated. The ethylcellulose: $2^{\text {nd }}$ polysaccharide blend ratio was 80:20 (weight:weight) in all cases. Thirty percent DBS (referring to ethylcellulose) was added as a plasticizer, the systems were loaded with $10 \%$ theophylline, the extrusion temperature was $100{ }^{\circ} \mathrm{C}$ in all cases. Cross-sections of the hot melt extrudates (obtained by manual breaking) are shown at the top, pictures of surfaces right below. As it can be seen, the inner structure of all systems appeared to be rather homogeneous and the surface relatively smooth, except for ethylcellulose:chitosan blends, which lead to extrudates with a slightly rough surface and somehow "granular" inner structure.

Importantly, in all cases the torque measured during extrusion was similar (around $30 \%$ ), not causing any difficulty during processing (Figure 2a). The resulting drug release kinetics upon exposure to $0.1 \mathrm{M} \mathrm{HCl}$ for $2 \mathrm{~h}$, followed by phosphate buffer $\mathrm{pH} 6.8$ for $22 \mathrm{~h}$ are illustrated in Figure 2b. Clearly, the type of polymer blend had a pronounced effect on theophylline release. This can be attributed to the different chemical structures of the 
polysaccharides and the resulting difference in permeability of the polymeric matrices for the drug. In many cases, the observed release rates were too low for oral administration (e.g. less than about $18 \%$ after 24 h). For this reason, only the 3 most rapidly releasing polymer blends were selected for further studies: ethylcellulose:chitosan, ethylcellulose:guar gum and ethylcellulose:pectin.

In an attempt to simplify the formulation, the plasticizer DBS was omitted. Figure 3 shows macroscopic pictures of cross-sections and surfaces of hot melt extrudates based on ethylcellulose:pectin/guar gum/chitosan blends free of plasticizer. The blend ratio was varied as indicated, hot melt extrudates based "only" on ethylcellulose (loaded with $10 \%$ theophylline) are shown for reasons of comparison. To allow for extrusion without a plasticizer, the processing temperature had to be increased, here to $170{ }^{\circ} \mathrm{C}$. As it can be seen in the top row, this temperature degraded pectin under the given conditions. Also, in the case of hot melt extrudates loaded with high amounts of chitosan some color changes at the systems' surface was observed (Figure 3, bottom row). Due to the important pectin degradation, these hot melt extrudates were not studied any further. The resulting theophylline release kinetics of systems based on different ethylcellulose:guar gum and ethylcellulose:chitosan blends are illustrated in Figure 4. The release medium was $0.1 \mathrm{M} \mathrm{HCl}$ for the first $2 \mathrm{~h}$, followed by phosphate buffer $\mathrm{pH} 6.8$ for the subsequent $6 \mathrm{~h}$. The ethylcellulose:2nd $2^{\text {nd }}$ polysaccharide blend ratio was varied as follows: 100:0, 90:10, 80:20, 70:30 and 60:40. As it can be seen, the resulting release rate was very low at all blend ratios in the case of ethylcellulose:chitosan (4 - $15 \%$ after $8 \mathrm{~h})$. Also in the case of ethylcellulose:guar gum blends, theophylline release from the plasticizer-free implants was relatively slow, much slower compared to the respective DBS-plasticized systems extruded at $100{ }^{\circ} \mathrm{C}$ : For example, after $8 \mathrm{~h}$ only 6 versus $15 \%$ drug was released in the case of ethylcellulose:guar gum 80:20 blends (see also Figure 4b versus Figure 2b). This reduced drug release rate in plasticizer-free systems can at least partially be attributed to the fact that 
the presence of the plasticizer increases the mobility of the polymer chains and, thus, also of the drug molecules. For example, Figure S2 shows the DSC thermogram of ethylcellulose plasticized with $30 \%$ DBS. The glass transition temperature decreased from about 130 to $53{ }^{\circ} \mathrm{C}$ in the dry state compared to pure ethylcellulose (Figure 5 vs. Figure S2). In addition to DBS, water can also be expected to be acting as a plasticizer for this polymer during drug release. Since the observed release rates were too low in plasticizer-free hot melt extrudates, these systems were not studied any further.

Instead, the suitability of ethylcellulose:guar gum, ethylcellulose:chitosan and ethylcellulose:HPMC E5 blends, plasticized with 30 \% DBS was studied in more detail (note that "pectin was replaced by HPMC E5", since it showed important thermal degradation at $170{ }^{\circ} \mathrm{C}$, and similar drug release rates: Figure 3 and Figure $2 \mathrm{~b}$ ). In the presence of the plasticizer, the extrusion temperature was again reduced to $100{ }^{\circ} \mathrm{C}$. Figure 6 shows the resulting theophylline release kinetics from hot melt extrudates based on these polymer:polymer blends, varying the blend ratio from 100:0 to 20:80, in $10 \%$ increments. The release medium was $0.1 \mathrm{M} \mathrm{HCl}$ for $2 \mathrm{~h}$, followed by phosphate buffer $\mathrm{pH} 6.8$ for $22 \mathrm{~h}$. Clearly, in all cases a broad spectrum of drug release patterns could be obtained, by simply varying the polymer:polymer blend ratio. In the investigated cases, ethylcellulose was less permeable for theophylline than the other polymers. This is why in all cases, the release rate increased with decreasing ethylcellulose content. Since ethylcellulose:guar gum blends showed the largest spectrum of possible drug release patterns (e.g., the highest theophylline release rate at the 20:80 ethylcellulose: $2^{\text {nd }}$ polysaccharide blend ratio), this blend was selected for further studies.

\subsection{Ethylcellulose:guar gum blends}

Figure 7 shows macroscopic pictures of cross-sections and surfaces of different types of ethylcellulose:guar gum based hot melt extrudates: The following parameters were varied: 
(i) the type of plasticizer (DBS, TEC and PEG), (ii) the percentage of plasticizer (15, 20 and $30 \%$, (iii) the extrusion temperature $\left(100\right.$ and $\left.170{ }^{\circ} \mathrm{C}\right)$, (iv) the screw speed $(30,60$ and $90 \mathrm{rpm}$ ), (v) the type of drug (theophylline and diprophylline, being slightly and freely watersoluble), and (vi) the drug loading (10, 30 and $60 \%$, referring to the total extrudate mass). In all cases, the ethylcellulose:guar gum blend ratio was kept constant: 80:20 (weight:weight). As it can be seen, in all cases rather homogeneous inner system structures and relatively smooth surfaces were obtained. In no case, any visible sign of polymer degradation was observed. Extrudates containing 0,15 or $20 \%$ plasticizer as well as extrudates loaded with $60 \%$ drug were hard and brittle. All other systems were flexible.

Figure 8a shows the torque values measured during the extrusion of ethylcellulose:guar gum 80:20 blends plasticized with $15 \%$ PEG (PEG 1500), DBS or TEC. The systems were loaded with $10 \%$ theophylline. For reasons of comparison, also the torque values observed with "pure" ethylcellulose hot melt extrudates (loaded with $10 \%$ theophylline) are shown. Please note that it was not possible to extrude plasticizer-free and $15 \%$ PEG containing formulations at $100{ }^{\circ} \mathrm{C}$ (the torque values were too high). This is why these extrudates were obtained at $170{ }^{\circ} \mathrm{C}$ processing temperature. In contrast, blends plasticized with $15 \%$ DBS or TEC could be obtained at $100{ }^{\circ} \mathrm{C}$ processing temperature, although the corresponding torque values were high (Figure 8a). The respective theophylline release kinetics from these hot melt extrudates are illustrated in Figure 8b. As it can be seen, the following rank order with respect to the resulting drug release rate was observed: $15 \%$ PEG $>15 \%$ DBS $>15 \%$ TEC $>$ no plasticizer. Thus, the plasticizer facilitates drug release, probably due to increased polymer chain mobility and/or plasticizer leaching into the surrounding bulk fluid. Please note that a direct comparison of PEG with DBS \& TEC should be viewed with caution, since the extrusion temperature was different. In all cases, the resulting drug release rates were rather low (e.g., less than $36 \%$ after $6 \mathrm{~h}$ ). 
Figure 9a shows the impact of varying the plasticizer content (here DBS and TEC) on the torque measured during extrusion of ethylcellulose:guar gum 80:20 blends, loaded with 10\% theophylline. The extrusion temperature was $100{ }^{\circ} \mathrm{C}$. Clearly, the torque values substantially decreased with increasing plasticizer level, irrespective of the type of plasticizer. The theophylline release kinetics from the obtained hot melt extrudates are shown in Figure 9b. Interestingly, the freely water-soluble plasticizer TEC lead to slower drug release rates than the lipophilic plasticizer DBS. Thus, in these cases, the increase in polymer chain mobility seems to play a more important role than potential plasticizer leaching into the surrounding bulk fluid (eventually creating water-filled pores). TEC seems to be a more efficient plasticizer for the polymeric matrix than DBS, resulting in a denser (and less permeable) system (overcompensating potential increased drug mobility effects). But again, in all cases the resulting theophylline release rates were rather low (e.g., less than $27 \%$ drug was released after $6 \mathrm{~h})$.

The effects of varying the screw speed when manufacturing ethylcellulose:guar gum 80:20 based hot melt extrudates loaded with $10 \%$ theophylline at $100{ }^{\circ} \mathrm{C}$ (plasticized with $30 \% \mathrm{DBS}$ ) on: a) the torque measured during extrusion, and b) drug release in $0.1 \mathrm{M} \mathrm{HCl}$ for $2 \mathrm{~h}$, followed by phosphate buffer pH 6.8 for subsequent $6 \mathrm{~h}$, are illustrated in Figure 10 . Clearly, the variation of the screw speed in the investigated range $(30-60-90 \mathrm{rpm})$ did neither substantially impact the torque, nor theophylline release.

Furthermore, the impact of the type of drug and drug loading was studied (Figure 11): The percentages of slightly water-soluble theophylline and freely water-soluble diprophylline were varied from 10 to $60 \%$. Figure 11a shows the respective torque values observed during extrusion (at $100{ }^{\circ} \mathrm{C}$, with $30 \%$ DBS). Figure $11 \mathrm{~b}$ shows the resulting drug release kinetics in $0.1 \mathrm{M} \mathrm{HCl}$ for $2 \mathrm{~h}$, followed by phosphate buffer $\mathrm{pH} 6.8$ for $22 \mathrm{~h}$. As it can be seen, the torque values increased with increasing drug loading (especially in the case of theophylline). This can probably be attributed to the fact that both drugs do not melt at $100{ }^{\circ} \mathrm{C}$ (Figure 5) and that 
the relative amounts of more easily extrudable, plasticized polymer blends in the formulations decrease. Figure $11 \mathrm{~b}$ shows that also the resulting drug release rates clearly increased with increasing drug loading. This can at least partially be explained by the fact that less drug release retarding polymer is present in the systems. Or, in other words: Upon drug release, the systems become more and more porous and remaining drug can more easily diffuse out. This is very important from a practical point of view: Most of the drug is released after $24 \mathrm{~h}$ at an initial drug loading of $60 \%$. Also, as it can be seen, about zero order release kinetics can be provided during major parts of the release periods: Theophylline and diprophylline were released at a rate of approximately $3 \% / \mathrm{h}$ during $24 \mathrm{~h}$. Please note that perfect sink conditions were provided throughout the experiments. Thus, the observed relatively constant drug release rates can probably be attributed to drug saturation effects within the hot melt extrudates: The amounts of water penetrating into the systems are limited and most likely not sufficient to dissolve the entire drug loadings. Thus, non-dissolved and dissolved drug co-exist within the systems. Importantly, only dissolved drug is available for diffusion. This results in about constant drug concentration differences: saturated solutions inside the hot melt extrudates and perfect sink conditions in the surrounding bulk fluids.

Figure 5 shows DSC thermograms of hot melt extrudates loaded with 10 to $60 \%$ diprophylline or theophylline, based on ethylcellulose:guar gum 80:20 blends plasticized with $30 \%$ DBS prepared at $100{ }^{\circ} \mathrm{C}$. For reasons of comparison, also the DSC thermograms of the following raw materials (as received) are illustrated: ethylcellulose, guar gum, DBS, diprophylline and theophylline. Pure ethylcellulose showed 2 thermal events: (i) a glass transition (Tg) at about $130{ }^{\circ} \mathrm{C}$, which is in good agreement with data reported in the literature [e.g., 41], and (ii) an exothermic event at approximately $185^{\circ} \mathrm{C}$. Lai et al. [42] have shown that for "Ethocel Standard 100 Premium" (an ethylcellulose with a higher molecular weight than the investigated polymer) (Dow, Midland, MI, USA) a similar exotherm corresponded to an oxidative degradation (the pans were hermetically closed, the nitrogen flushing was 
outside the pans), which masks the melting of a small crystalline fraction. The presence of a small crystalline fraction in the ethylcellulose raw material was further confirmed by X-ray powder diffraction measurements (Figure S3). A Bragg peak was visible at about $2 \Theta=12^{\circ}$. Also, Huang et al. [43] reported a Bragg peak for another ethylcellulose ("N7 viscosity grade", 48.0 - $49.5 \mathrm{w} / \mathrm{w}$ ethoxyl groups) (Hercules, Wilmington, DE, USA) in this range. Furthermore, TGA revealed thermal degradation of ethylcellulose above $200^{\circ}$ (Figure S4).

The guar gum raw material was X-ray amorphous (Figure S3). The DSC thermogram showed a glass transition at about $60^{\circ} \mathrm{C}$ and an exothermic event between 250 and $300{ }^{\circ} \mathrm{C}$, corresponding to thermal degradation, as confirmed by TGA (Figure S4). This is also consistent with data reported in the literature [e.g., 44]. The TGA curve also indicates a mass loss of about $10 \%$ between $20{ }^{\circ} \mathrm{C}$ and approximately $125^{\circ} \mathrm{C}$, likely corresponding to water loss. DBS is a liquid at room temperature, melting at approximately $-10{ }^{\circ} \mathrm{C}$. Diprophylline and theophylline showed sharp melting endotherms at about 162 and $275^{\circ} \mathrm{C}$, respectively, indicating their crystalline nature. In the different types of hot melt extrudates (except for hot melt extrudates loaded with $10 \%$ theophylline) such endotherms could also be observed, but shifted toward lower temperatures (probably corresponding more to the dissolution of drug crystallites into their amorphous environment, rather than to melting). So, the diprophylline is at least partially distributed in the form of small crystals throughout the hot melt extrudates at all the investigated drug loadings. In contrast, theophylline is likely completely dissolved and/or amorphous at $10 \%$ drug loading, and at least partially dispersed in the form of small crystals at 30 and $60 \%$ drug loading.

Since guar gum has been reported to be preferentially degraded by enzymes secreted by bacteria present in the colon [e.g., 45,46,47] and since the provided drug release periods were rather long, it was important to evaluate whether or not the exposure to fecal samples potentially altered the resulting drug release kinetics from the investigated hot melt extrudates. Due to the intimate mixture of guar gum with ethylcellulose, it might be that the 
latter effectively protects the guar gum against enzymatic degradation. For this reason, hot melt extrudates loaded with $60 \%$ theophylline or $60 \%$ diprophylline, based on ethylcellulose:guar gum 80:20 blends (plasticized with $30 \%$ DBS) were prepared at $100{ }^{\circ} \mathrm{C}$ and exposed to $0.1 \mathrm{M} \mathrm{HCl}$ for $2 \mathrm{~h}$, followed by phosphate buffer $\mathrm{pH} 6.8$ for $6 \mathrm{~h}$, and fecal samples for $10 \mathrm{~h}$ (the latter under anaerobic conditions). For reasons of comparison, the extrudates were also exposed to $0.1 \mathrm{M} \mathrm{HCl}$ and phosphate buffer $\mathrm{pH}$ 6.8, followed by culture medium free of fecal bacteria. The $0.1 \mathrm{M} \mathrm{HCl}$ was intended to simulate the conditions in the stomach, the phosphate buffer $\mathrm{pH} 6.8$ in the small intestine, and the fecal samples the conditions in the colon. The solid curves in Figure 12 show the experimentally measured drug release rates with this set up using fecal samples, whereas the dashed curves show the respective release rates observed with culture medium free of feces. As it can be seen, the presence of fecal bacteria did not have a noteworthy impact on drug release, irrespective of the type of drug.

Furthermore, the long term stability of the investigated hot melt extrudates was studied. Figure S5 shows the release rates of diprophylline and theophylline from ethylcellulose:guar gum 80:20-based systems in $0.1 \mathrm{M} \mathrm{HCl}$ for $2 \mathrm{~h}$, followed by $22 \mathrm{~h}$ in phosphate buffer $\mathrm{pH}$ 6.8. The drug loading were varied from 10 to $60 \%$, the extrudates were prepared at $100{ }^{\circ} \mathrm{C}$ and contained $30 \%$ DBS. The solid curves illustrate drug release prior to storage, the dashed curves drug release after 1 year storage at ambient conditions. In all cases, drug release did not change to a noteworthy extent. 


\section{Conclusion}

Hot melt extrudates based on ethylcellulose:guar gum blends offer an interesting potential as controlled drug delivery systems: They can be prepared at temperatures of about $100{ }^{\circ} \mathrm{C}$, provide broad spectra of drug release patterns (in particular about constant drug release rates) and are long term stable. The ethylcellulose can effectively protect the guar gum against potential enzymatic degradation in the colon.

\section{Acknowledgements}

This project has received funding from the Interreg 2 Seas programme 2014-2020, cofunded by the European Regional Development Fund under subsidy contract 2S01059_IMODE. The authors are very grateful for this support.

\section{Conflicts of interest}

One of the authors is the Editor-in-Chief of this journal. The manuscript has been subject to all of the journal's usual procedures, including peer review, which has been handled independently of the Editor-in-Chief. 


\section{Figure captions}

Fig. 1: Macroscopic pictures of hot melt extrudates (cross-sections and surfaces) based on ethylcellulose and different types of a $2^{\text {nd }}$ polymer (indicated in the figure). The polymer:polymer blend ratio was 80:20, the extrudates were extruded at $100{ }^{\circ} \mathrm{C}$, loaded with $10 \%$ theophylline and plasticized with $30 \%$ DBS. For reasons of comparison, also hot melt extrudates based "only" on ethylcellulose (loaded with $10 \%$ theophylline, and plasticized with $30 \%$ DBS) are illustrated.

Fig. 2: Impact of the type of polymer blend (indicated in the diagrams) used as matrix former on: a) the torque generated during hot melt extrusion, and b) theophylline release from the extrudates in $0.1 \mathrm{M} \mathrm{HCl}$ for $2 \mathrm{~h}$, followed by phosphate buffer $\mathrm{pH}$ 6.8. The extrudates were extruded at $100{ }^{\circ} \mathrm{C}$, loaded with $10 \%$ drug and plasticized with $30 \%$ DBS.

Fig. 3: Macroscopic pictures of hot melt extrudates (cross-sections and surfaces) based on ethylcellulose and different types of a $2^{\text {nd }}$ polymer (indicated in the figure). The polymer:polymer blend ratio is indicated in the figure, the extrudates were extruded at $170{ }^{\circ} \mathrm{C}$, loaded with $10 \%$ theophylline and free of plasticizer.

Fig. 4: Impact of the polymer:polymer blend ratio (indicated in the diagrams) on theophylline release from hot melt extrudates based on ethylcellulose:guar gum or ethylcellulose:chitosan blends (as indicated) in $0.1 \mathrm{M} \mathrm{HCl}$ for $2 \mathrm{~h}$, followed by phosphate buffer $\mathrm{pH} 6.8$. The extrudates were extruded at $170{ }^{\circ} \mathrm{C}$, loaded with $10 \%$ drug and free of plasticizer.

Fig. 5: DSC thermograms of hot melt extrudates based on 80:20 ethylcellulose:guar gum blends. The type and amount of drug were varied as indicated. The extrusion temperature was $100{ }^{\circ} \mathrm{C}$, the extrudates were plasticized with $30 \%$ DBS. For reasons of comparison, also the DSC thermograms of the pure drugs, polymer powders and DBS (all as received) are illustrated. 
Fig. 6: Impact of the polymer:polymer blend ratio (indicated in the figure) on theophylline release from hot melt extrudates based on ethylcellulose and different types of a $2^{\text {nd }}$ polysaccharide in $0.1 \mathrm{M} \mathrm{HCl}$ for $2 \mathrm{~h}$, followed by phosphate buffer $\mathrm{pH} 6.8$. The extrudates were extruded at $100{ }^{\circ} \mathrm{C}$, loaded with $10 \%$ drug and plasticized with $30 \%$ DBS.

Fig. 7: Macroscopic pictures of hot melt extrudates (cross-sections and surfaces) based on 80:20 ethylcellulose:guar gum blends. The types and amounts of drug and plasticizer, extrusion temperature and screw speed were varied as indicated.

Fig. 8: Impact of the type of plasticizer and extrusion temperature on: a) the generated torque, and b) theophylline release from extrudates in $0.1 \mathrm{M} \mathrm{HCl}$ for $2 \mathrm{~h}$, followed by phosphate buffer $\mathrm{pH}$ 6.8. The systems were based on 80:20 ethylcellulose:guar gum blends, the drug loading was $10 \%$.

Fig. 9: Impact of the type and amount of plasticizer on: a) the generated torque, and b) theophylline release from extrudates in $0.1 \mathrm{M} \mathrm{HCl}$ for $2 \mathrm{~h}$, followed by phosphate buffer $\mathrm{pH}$ 6.8. The systems were based on 80:20 ethylcellulose:guar gum blends, the extrusion temperature was $100{ }^{\circ} \mathrm{C}$ and the drug loading $10 \%$.

Fig. 10: Impact of the screw speed during extrusion of 80:20 ethylcellulose:guar gum blends on: a) the generated torque, and b) theophylline release from extrudates in $0.1 \mathrm{M} \mathrm{HCl}$ for $2 \mathrm{~h}$, followed by phosphate buffer $\mathrm{pH} 6.8$. The extrusion temperature was $100^{\circ} \mathrm{C}$, the extrudates were plasticized with $30 \%$ DBS, and the drug loading was $10 \%$.

Fig. 11: Impact of the theophylline or diprophylline loading on: a) the generated torque, and b) drug release from extrudates in $0.1 \mathrm{M} \mathrm{HCl}$ for $2 \mathrm{~h}$, followed by phosphate buffer pH 6.8. The systems were based on 80:20 ethylcellulose:guar gum blends, the extrusion temperature was $100^{\circ} \mathrm{C}$, the extrudates were plasticized with $30 \%$ DBS.

Fig. 12: Drug release from hot melt extrudates based on 80:20 ethylcellulose:guar gum blends under conditions simulating the transit through the entire gastro intestinal tract: $2 \mathrm{~h}$ in 
$0.1 \mathrm{M} \mathrm{HCl}$, followed by $6 \mathrm{~h}$ in phosphate buffer $\mathrm{pH} 6.8$, followed by culture medium inoculated with human fecal samples (solid curves). For reasons of comparison also drug release in $0.1 \mathrm{M} \mathrm{HCl}$, phosphate buffer $\mathrm{pH} 6.8$ and culture medium without fecal samples is shown (dotted curves). The drug loading was $60 \%$, the extrusion temperature $100{ }^{\circ} \mathrm{C}$. The extrudates were plasticized with $30 \%$ DBS. 
Pure EC

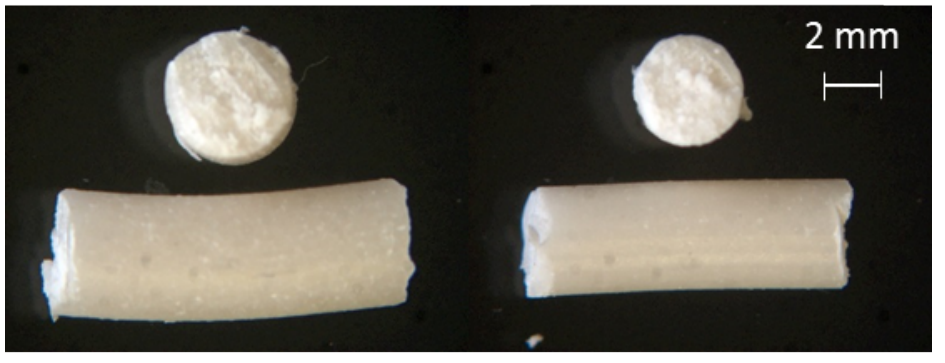

EC:Pectin

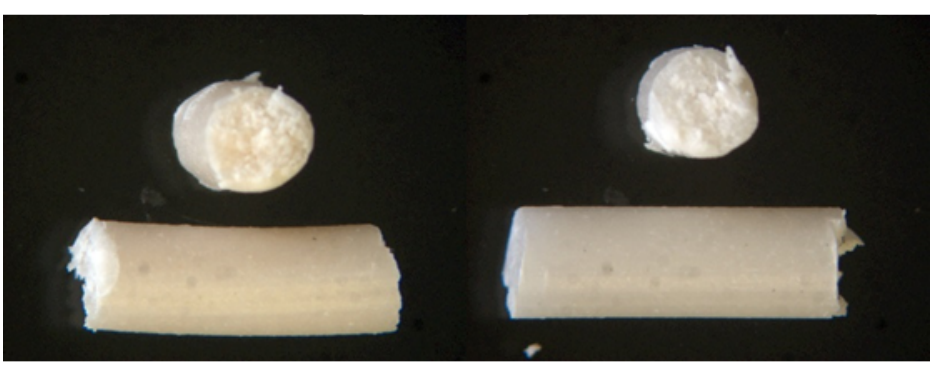

EC:Inulin

EC:Maltodextrin

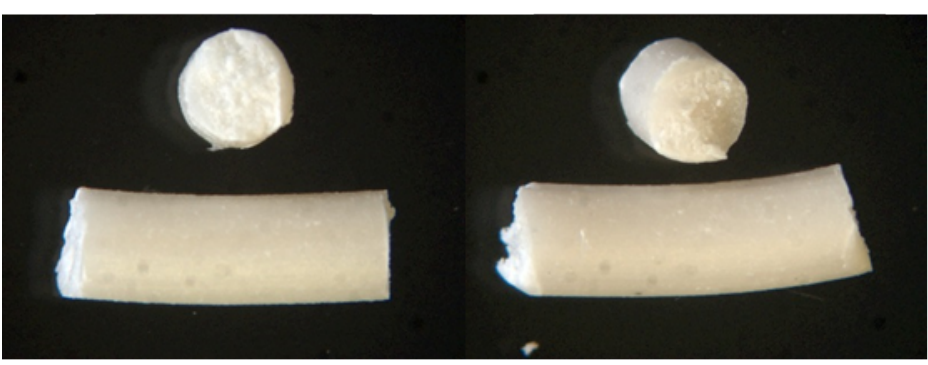

EC:Guar gum

EC:Chitosan

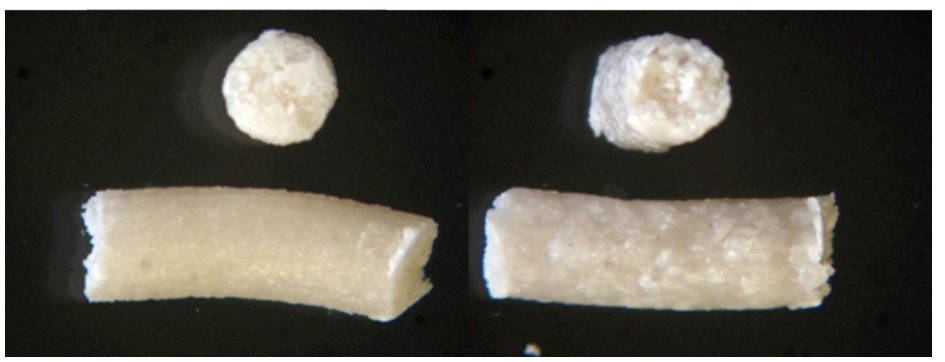

Figure 1 
a)
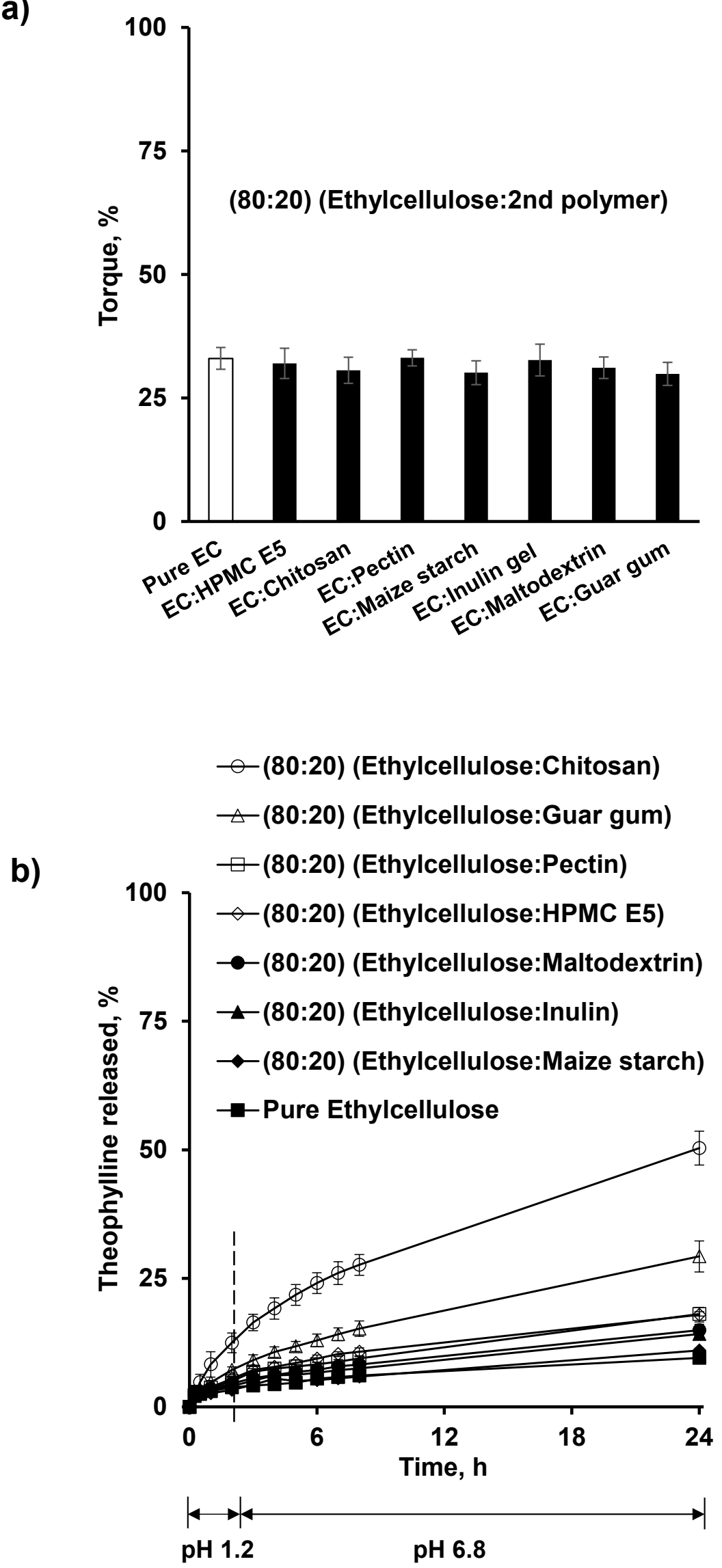

Figure 2 


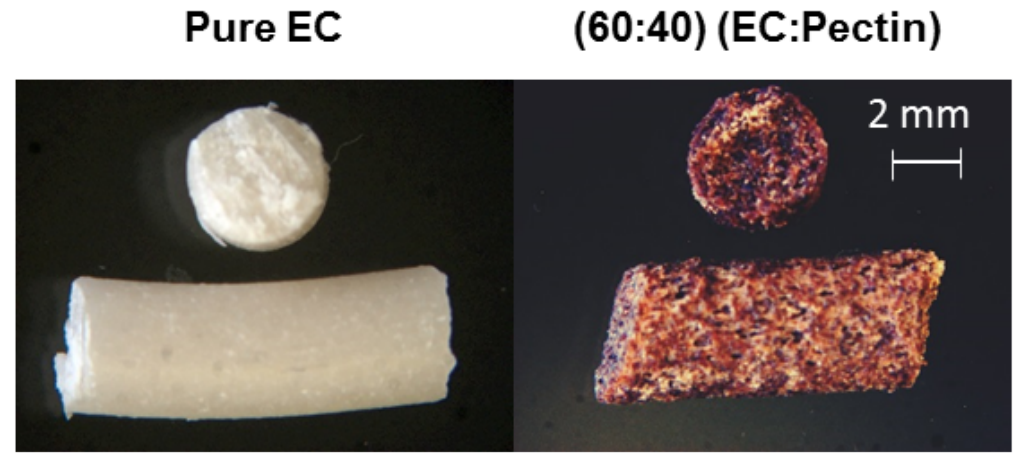

(EC:Guar gum)

(EC:Chitosan)

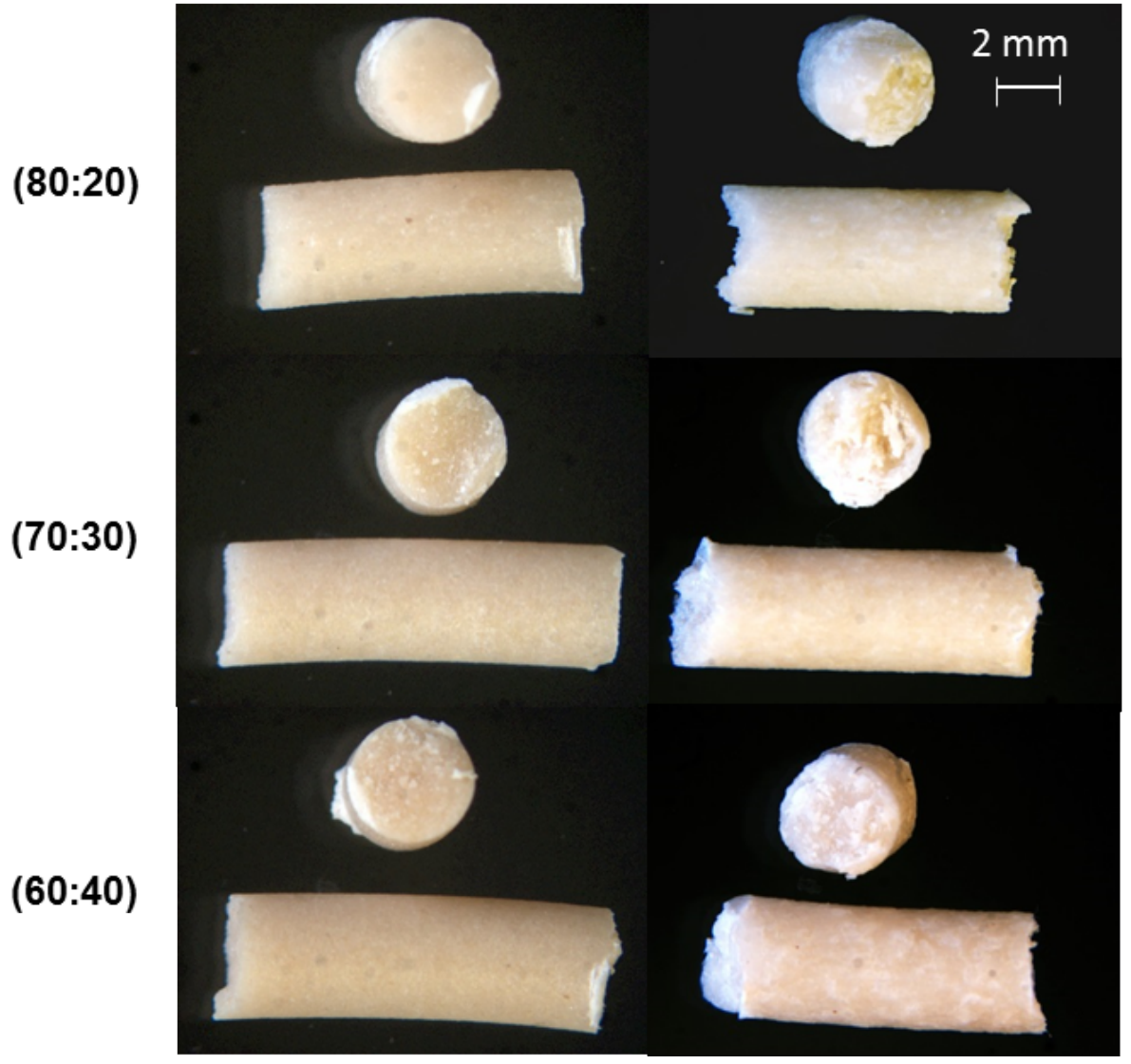

Figure 3 

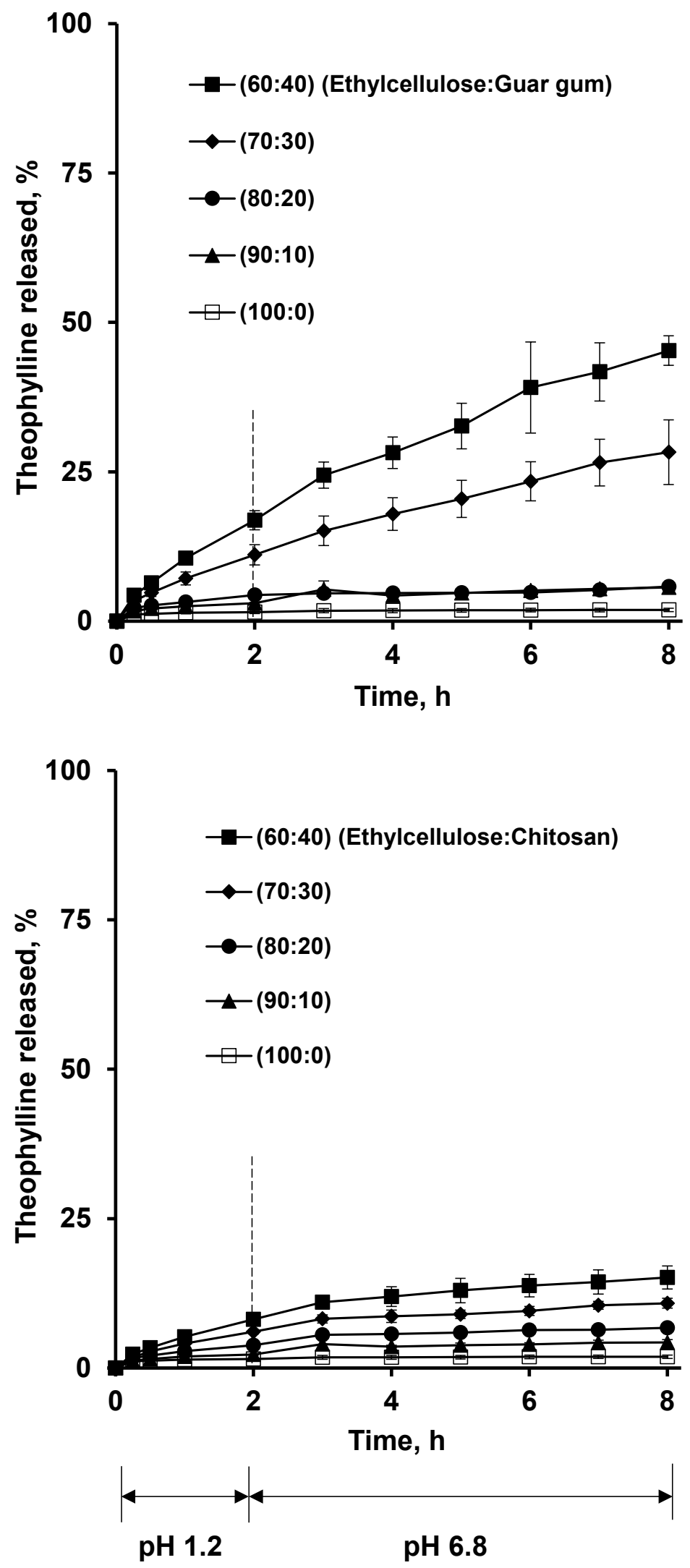

Figure 4 


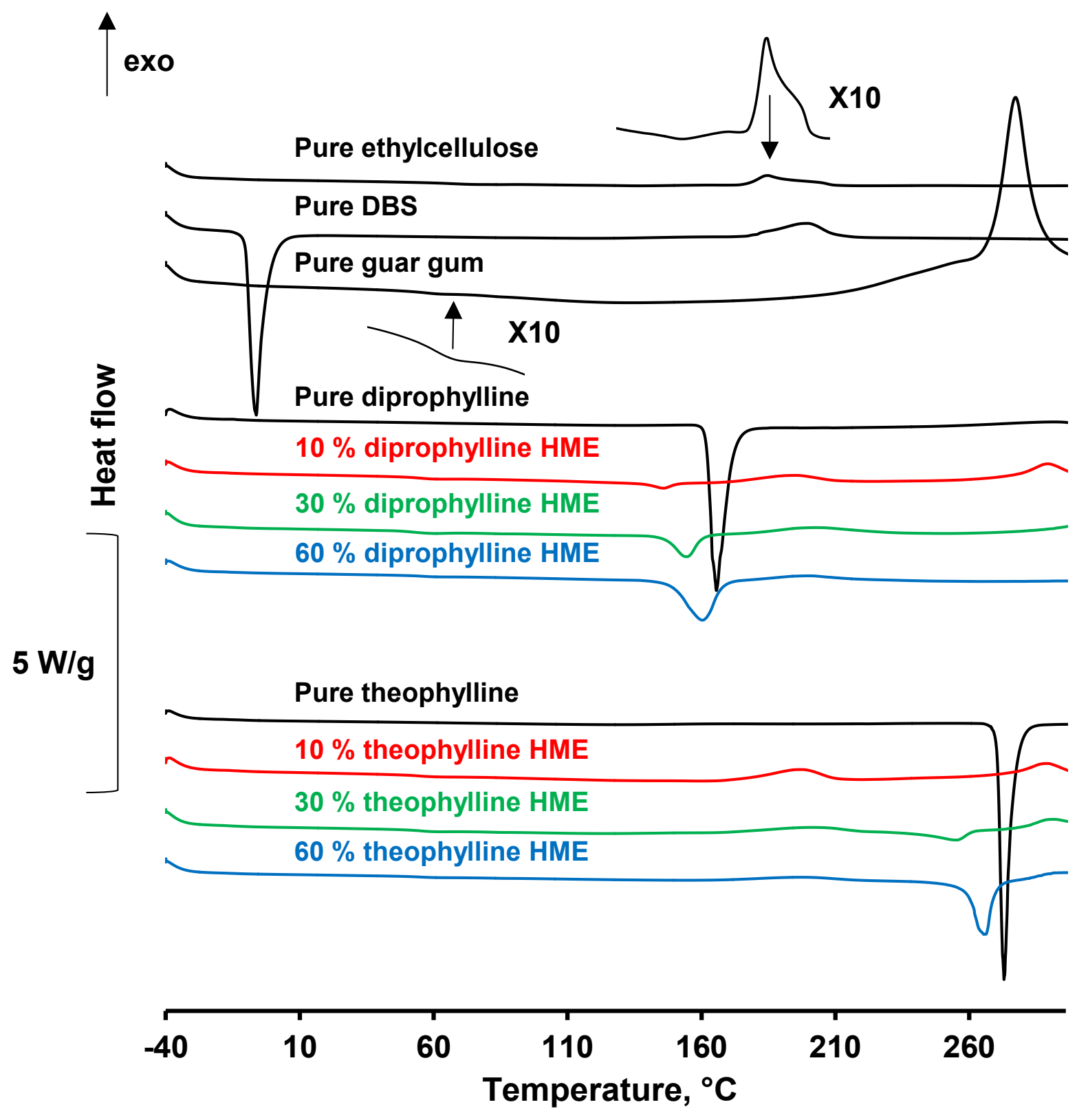

Figure 5 


\section{Ethylcellulose:Guar gum}

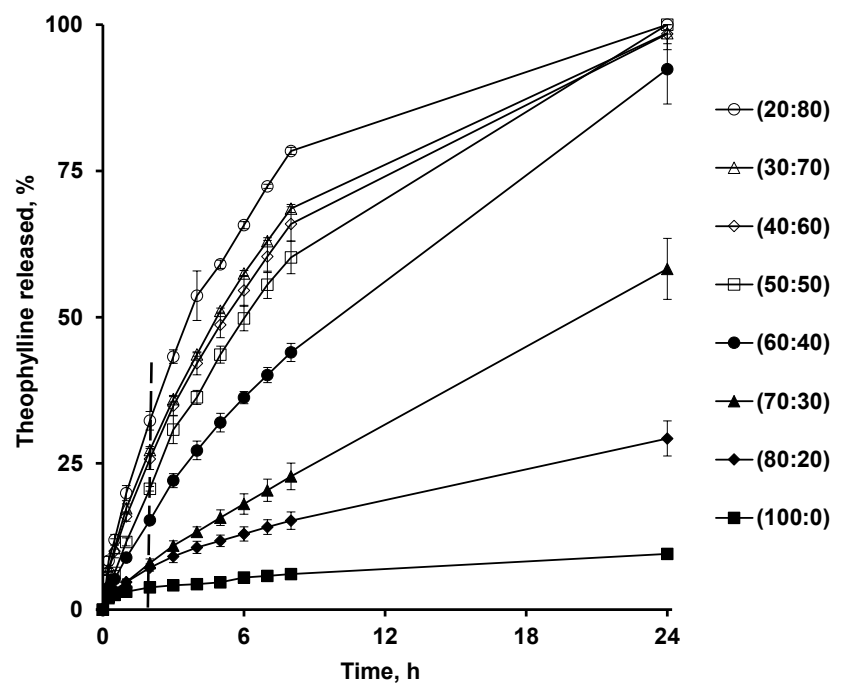

Ethylcellulose:Chitosan

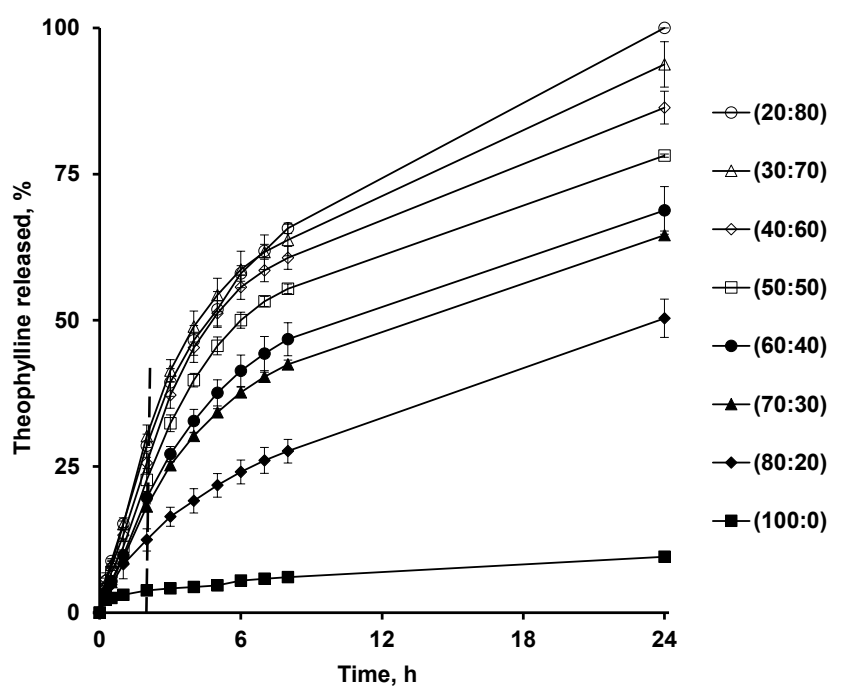

Ethylcellulose:HPMC E5

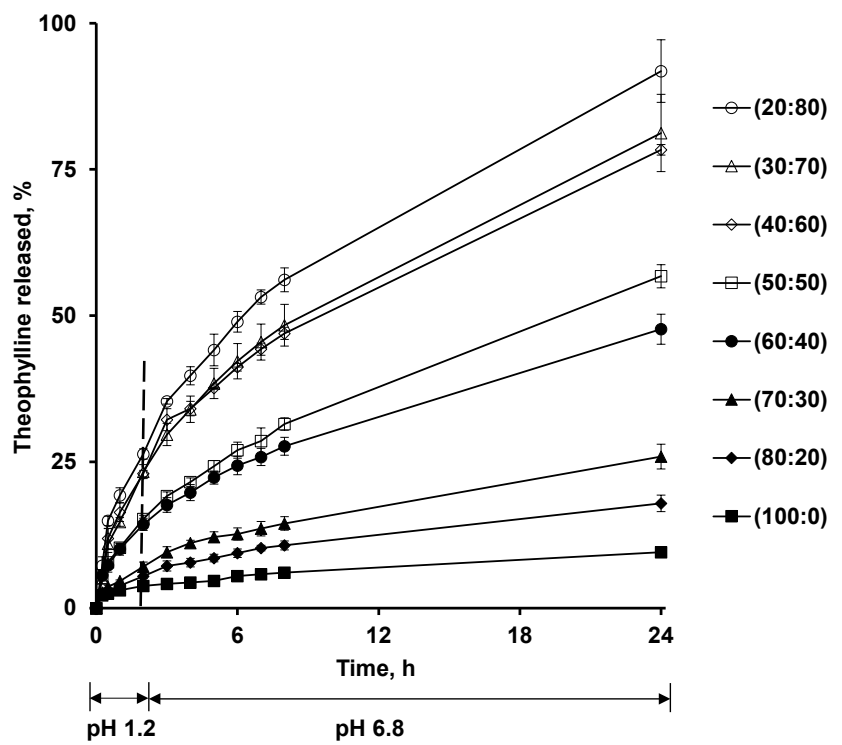

Figure 6 


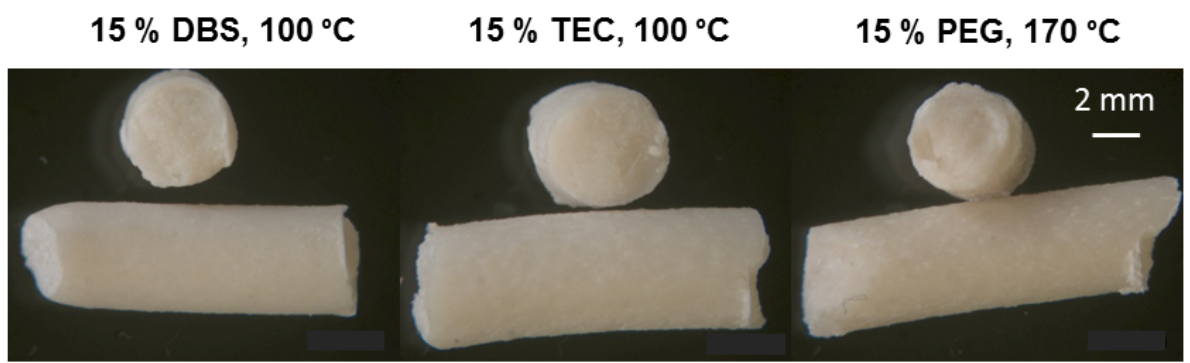

$30 \mathrm{rpm}$

$10 \%$ theophylline

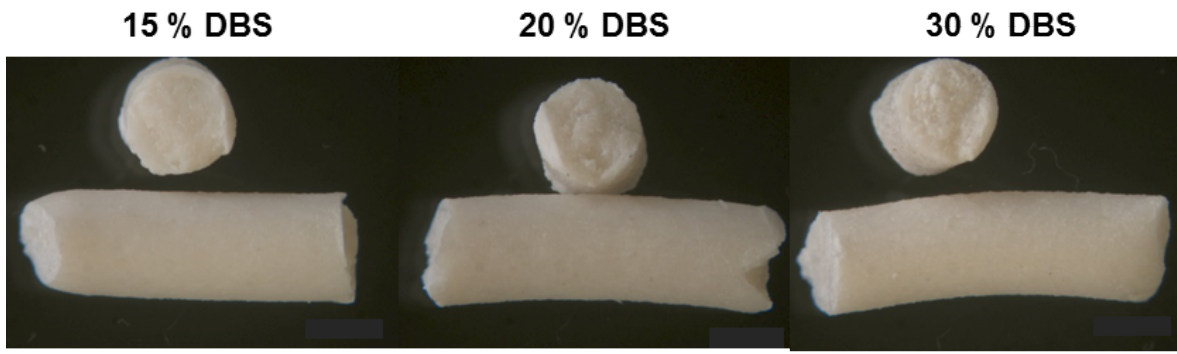

$100^{\circ} \mathrm{C}$

$30 \mathrm{rpm}$

$10 \%$ theophylline

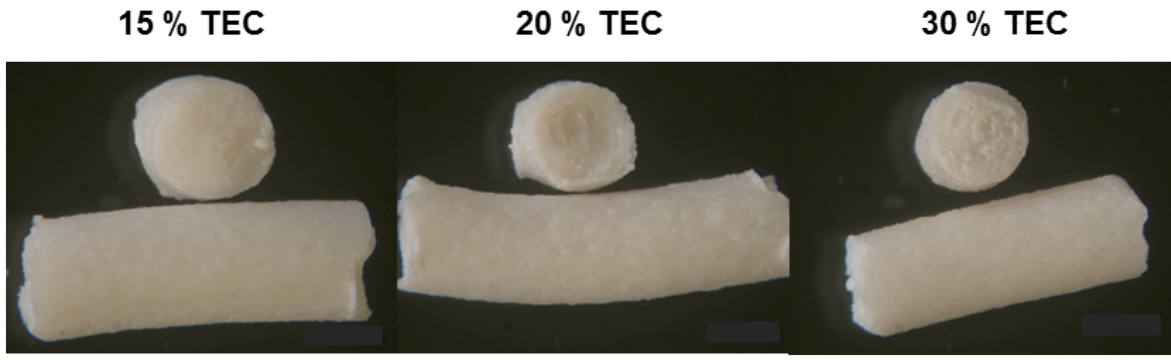

$100{ }^{\circ} \mathrm{C}$

$30 \mathrm{rpm}$

$10 \%$ theophylline

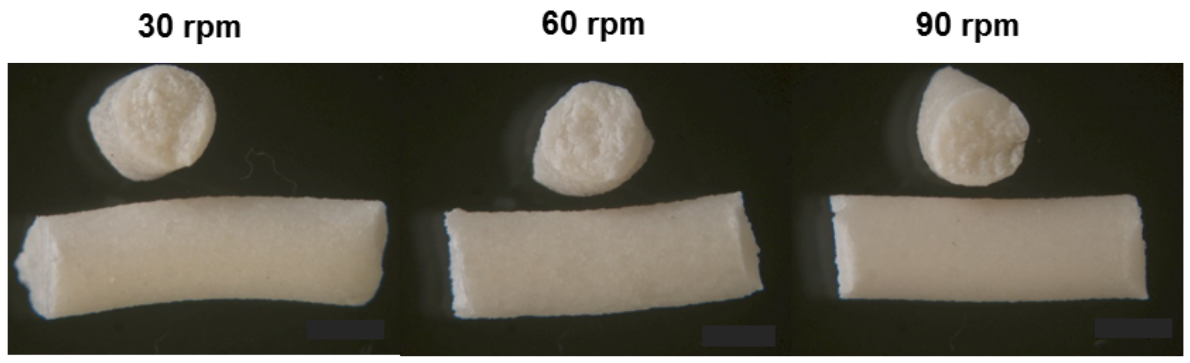

$30 \%$ DBS

$100^{\circ} \mathrm{C}$

$10 \%$ theophylline

$10 \%$ Theophylline

$30 \%$ Theophylline

$60 \%$ Theophylline

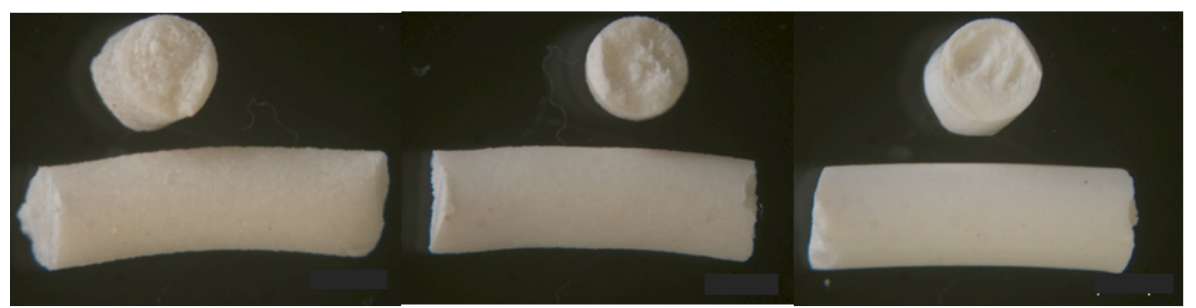

$30 \%$ DBS

$100^{\circ} \mathrm{C}$

$30 \mathrm{rpm}$
$10 \%$ Diprophylline
$30 \%$ Diprophylline
$60 \%$ Diprophylline

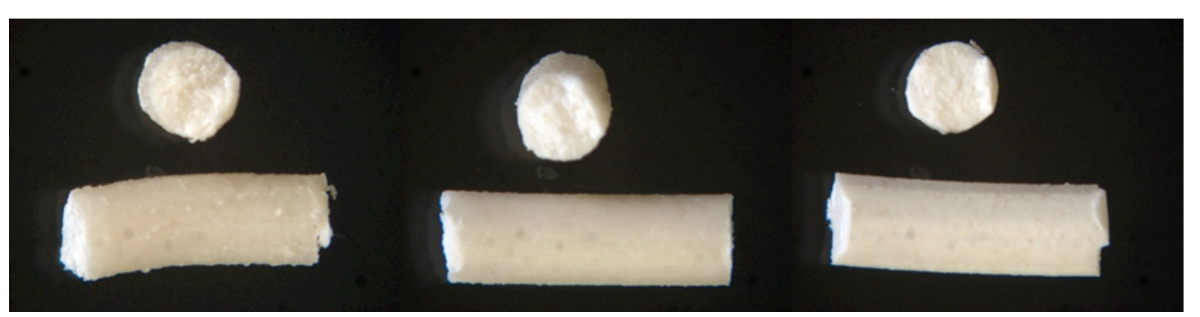

$30 \%$ DBS

$100{ }^{\circ} \mathrm{C}$

$30 \mathrm{rpm}$

Figure 7 
a)

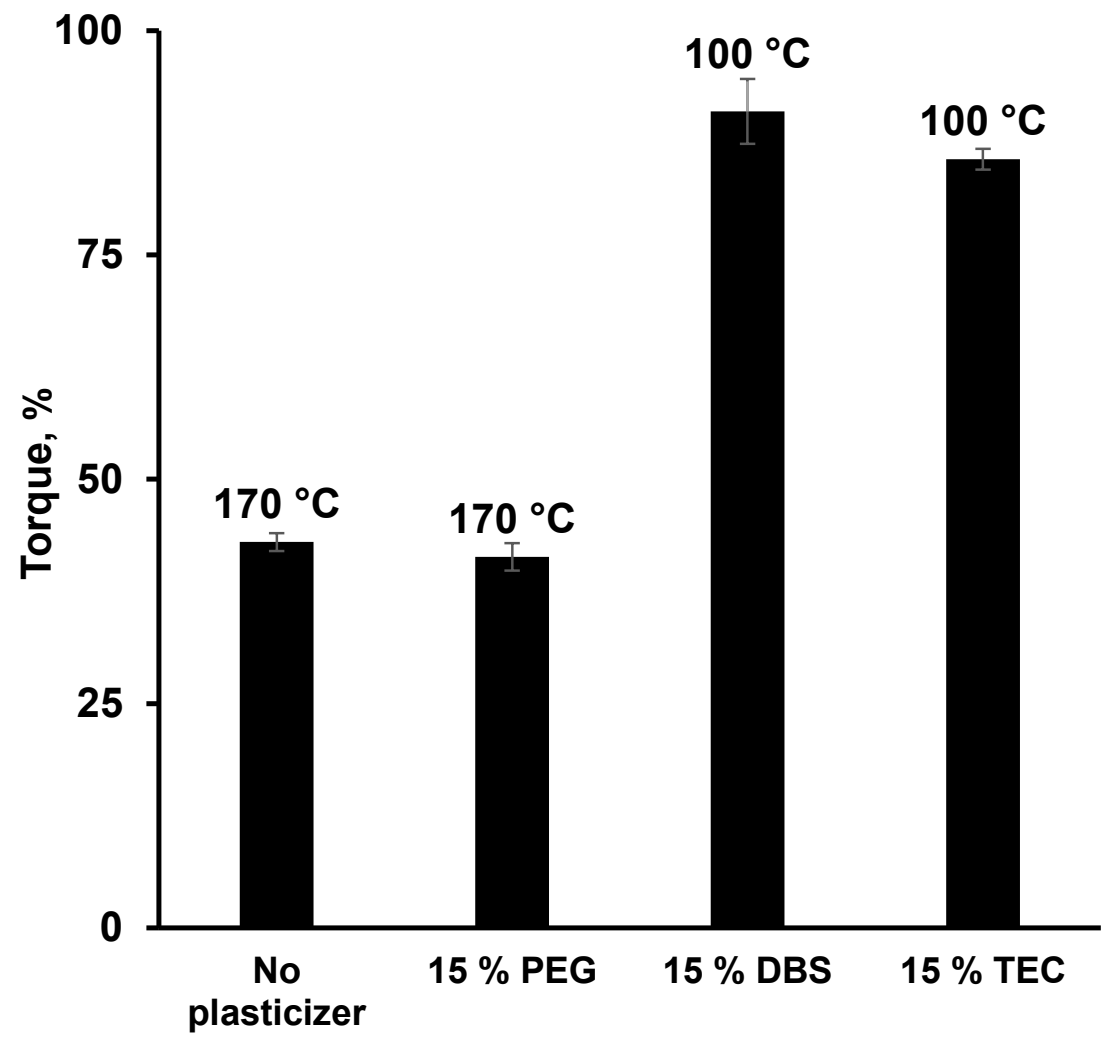

b)

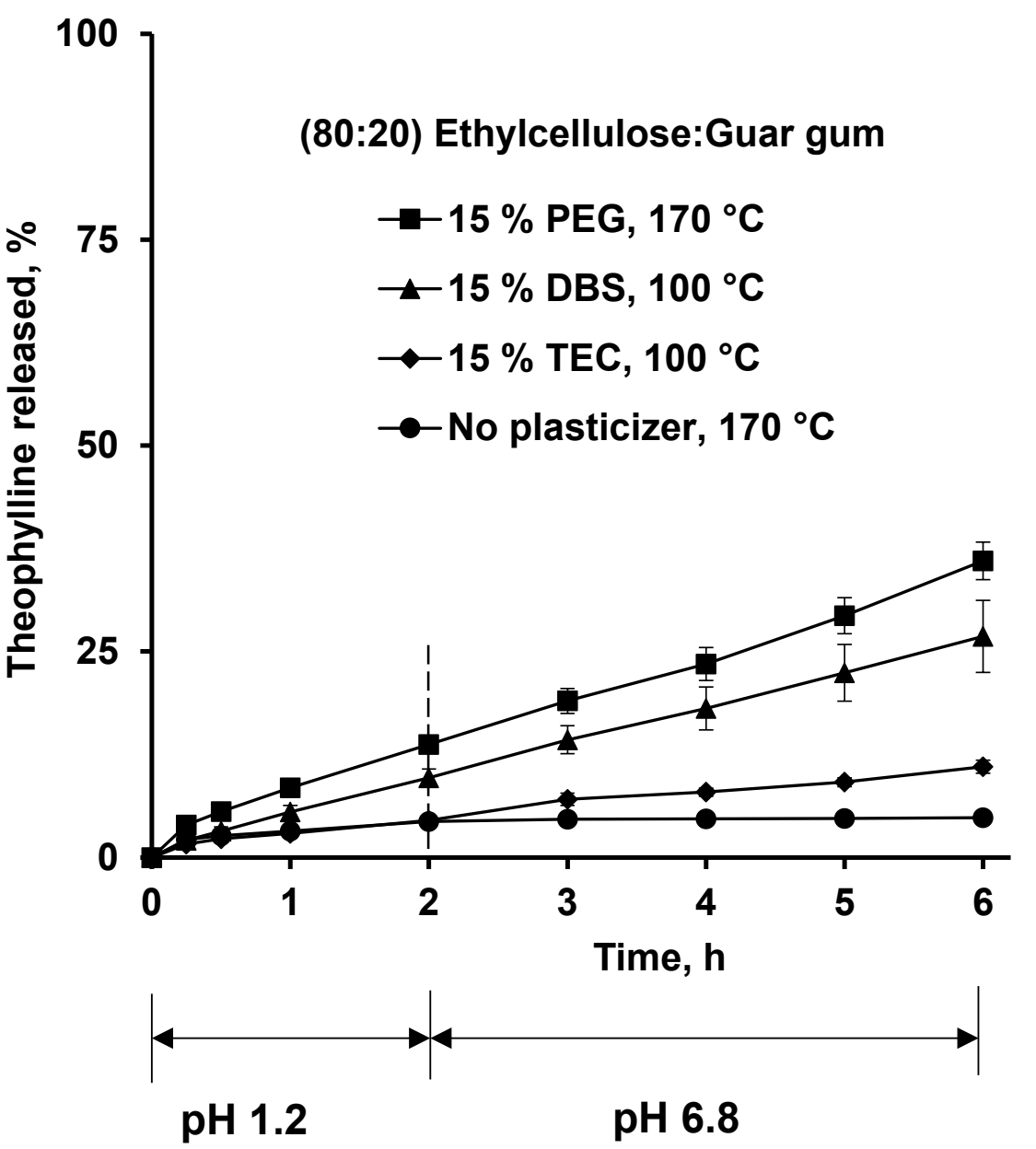

Figure 8 

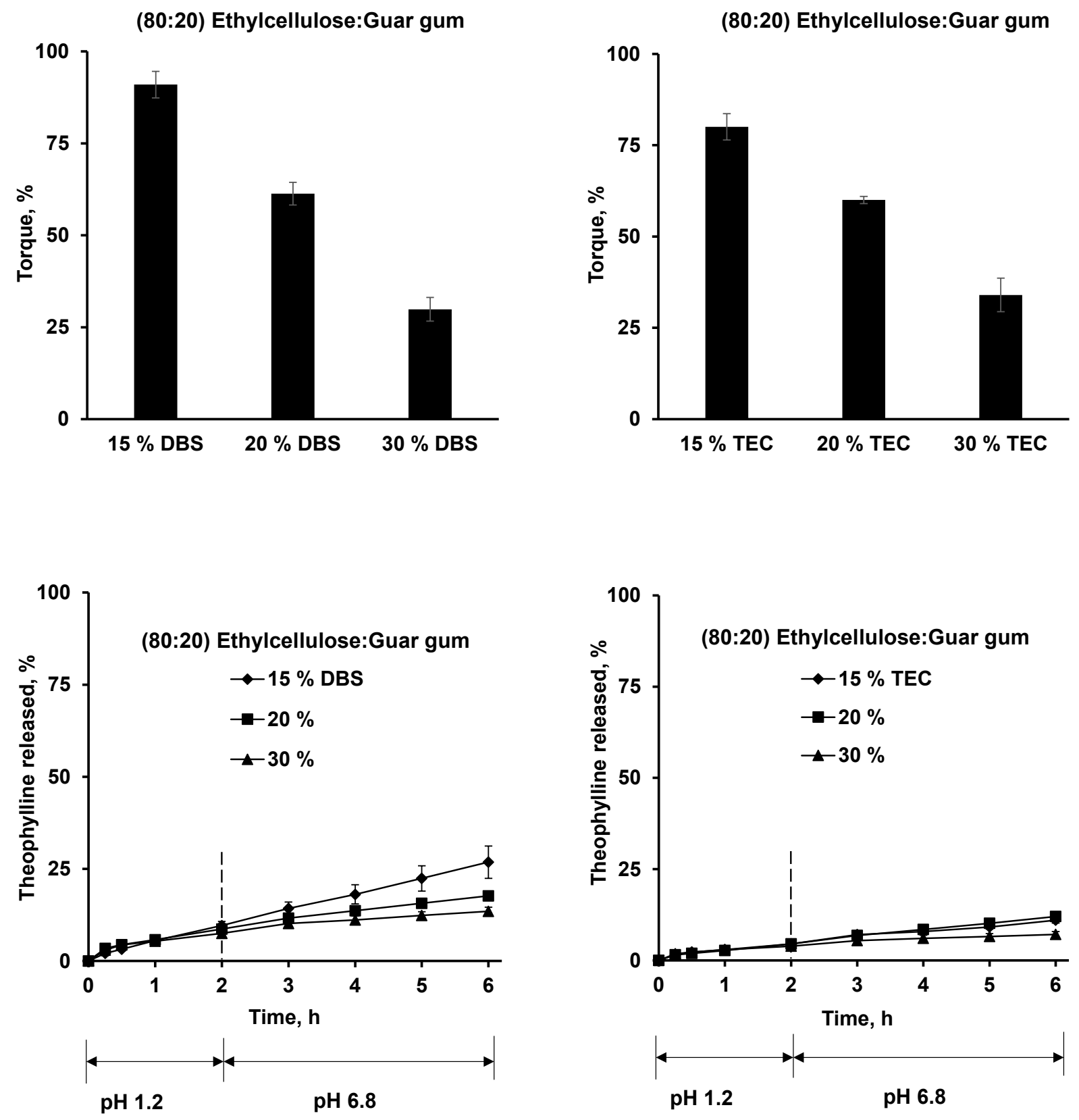

Figure 9 
a)

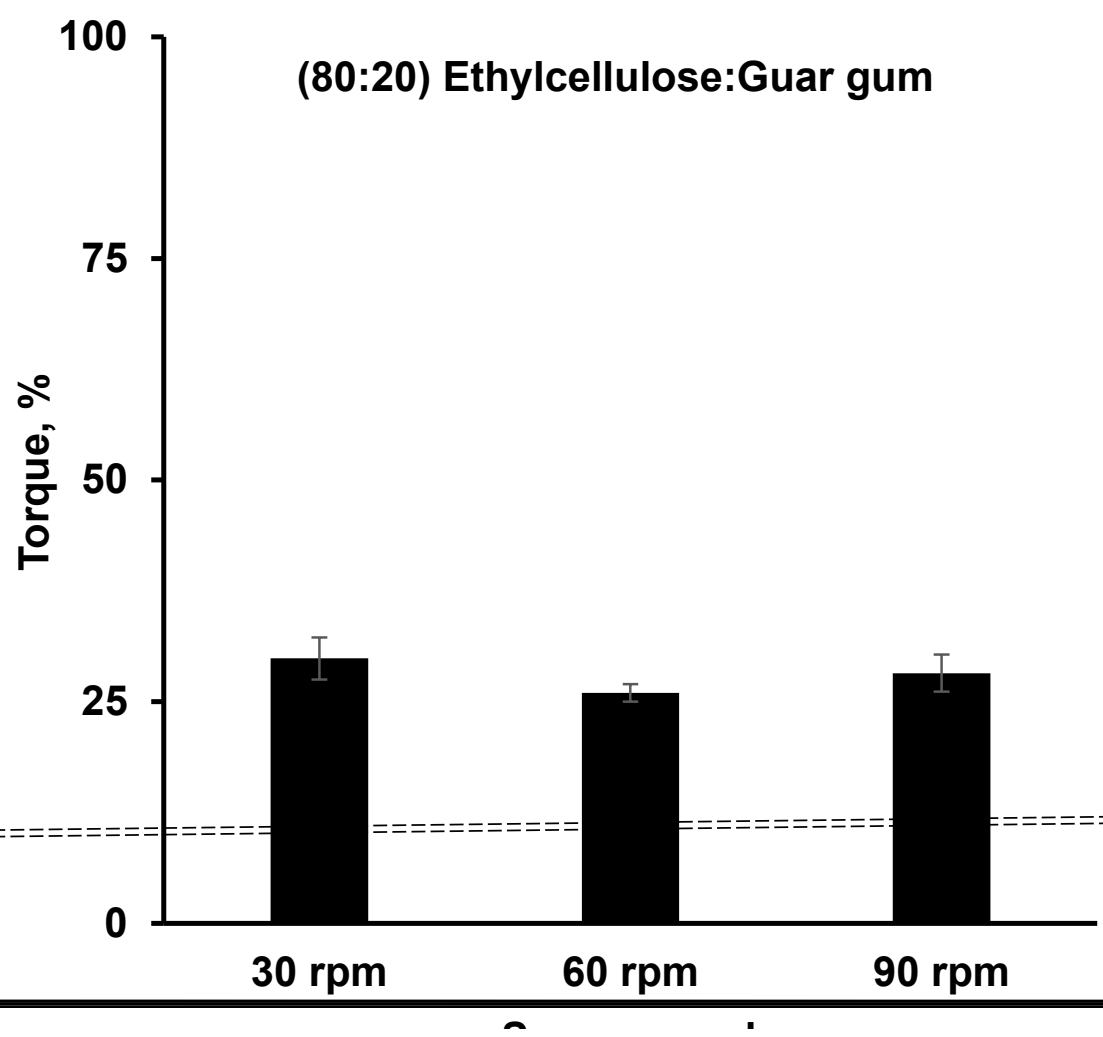

0

b)

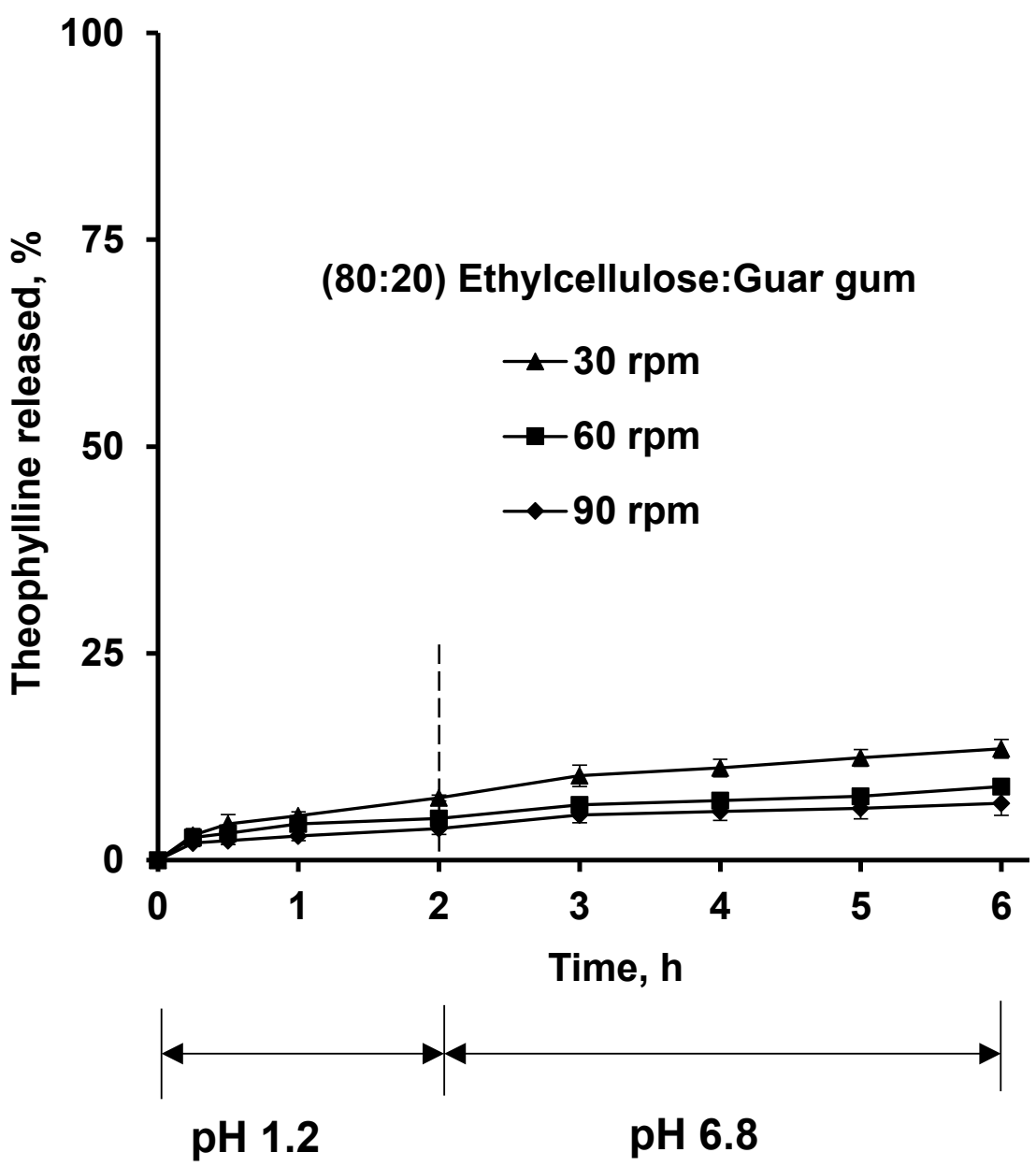

Figure 10 
a)

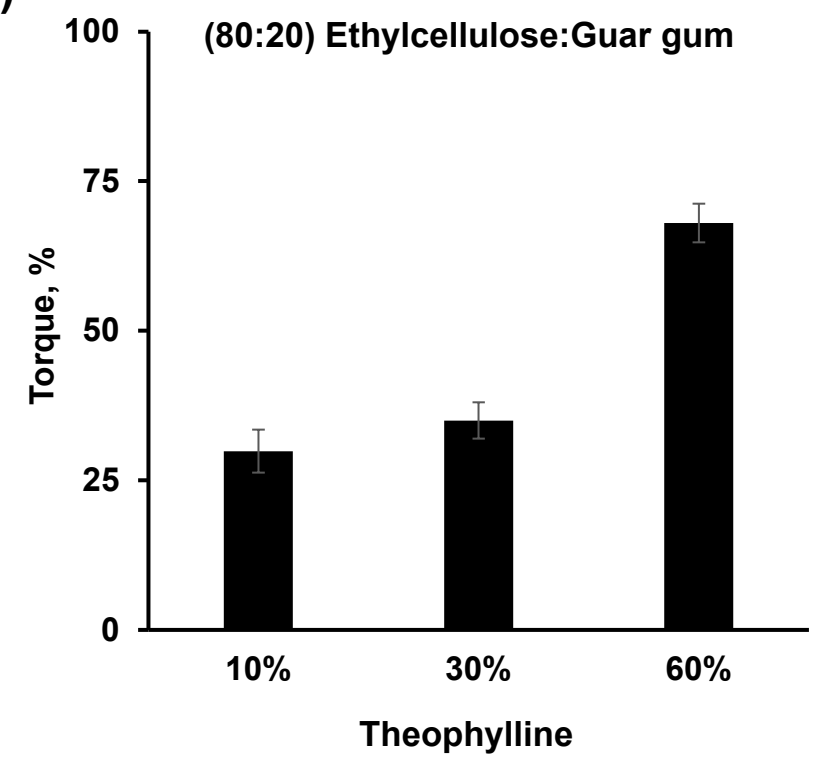

b)

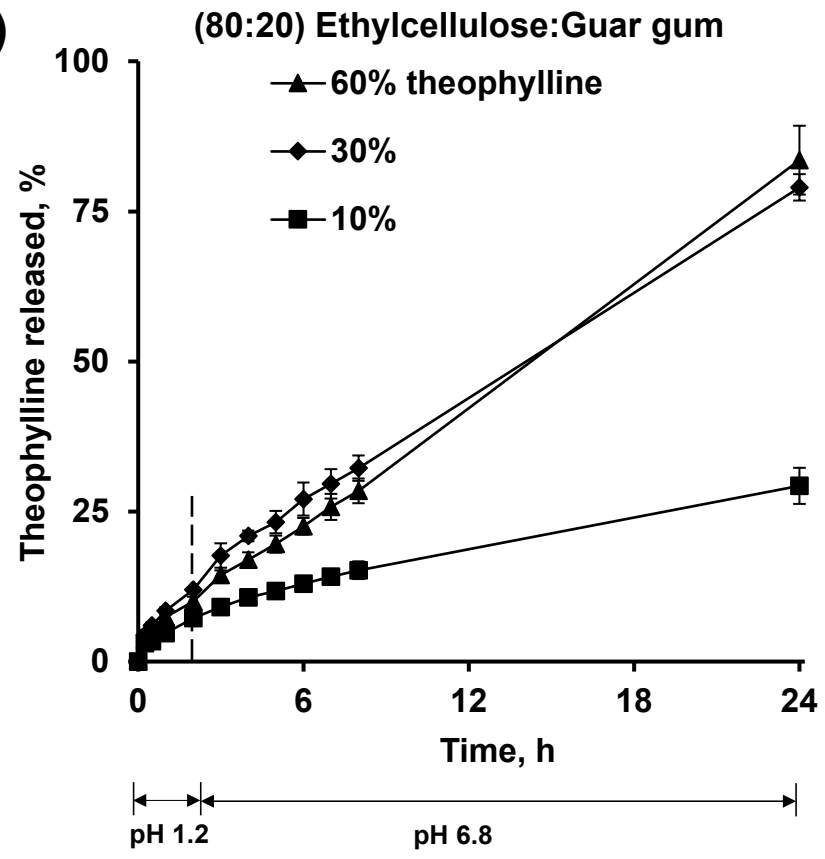

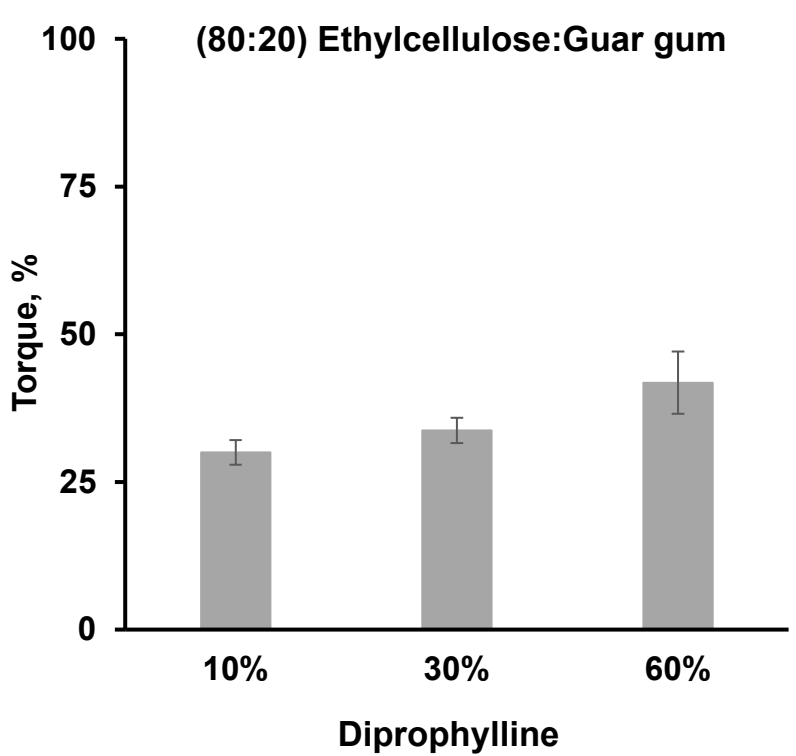

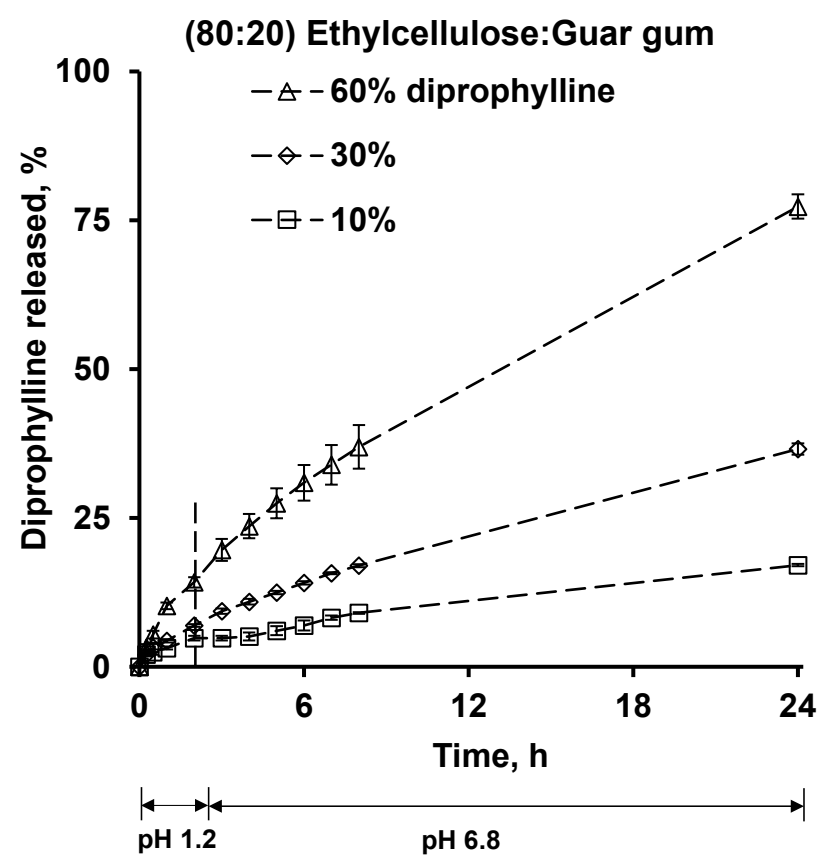

Figure 11 


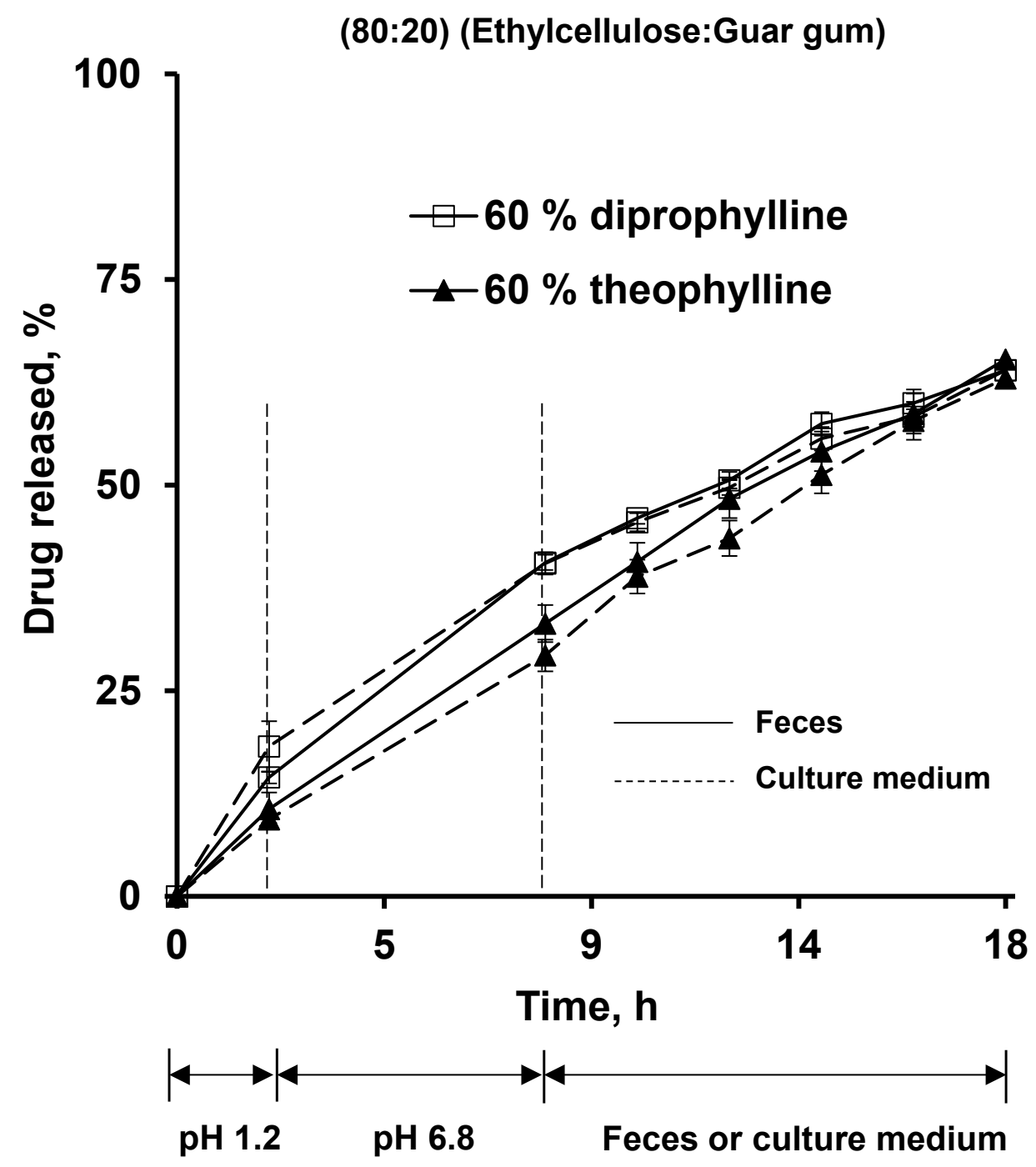

Figure 12 


\section{References}

[1] L. Palugan, M. Cerea, L. Zema, A. Gazzaniga, A. Maroni, Coated pellets for oral colon delivery, J. Drug Deliv. Sci. Technol. 25 (2015) 1-15.

[2] H. Häbel, H. Andersson, A. Olsson, E. Olsson, A. Särkkä, Characterization of pore structure of polymer blended films used for controlled drug release, J. Control. Release $222(2016) 151-158$.

[3] H. Andersson Moore, M. Marucci, L. Härdelin, J. Hjärtstam, A. Larsson, New insights on the influence of manufacturing conditions and molecular weight on phase-separated films intended for controlled release, Int. J. Pharmaceut. 536 (2018) 261-271.

[4] K. Madhumathi, L. Jeevana Rekha, T. S. Sampath Kumar, Tailoring antibiotic release for the treatment of periodontal infrabony defects using bioactive gelatin-alginate/apatite nanocomposite films, J. Drug Deliv. Sci. Technol. 43 (2018) 57-64.

[5] H. Li, Q. Sang, J. Wu, G. R. Williams, L-M. Zhu, Dual-responsive drug delivery systems prepared by blend electrospinning, Int. J. Pharmaceut. 543 (2018) 1-7.

[6] Neslihan Üstündağ Okur, Maria Filippousi, Mehmet Evren Okur, Şule Ayla, Panoraia I. Siafaka, A novel approach for skin infections: Controlled release topical mats of poly(lactic acid)/poly(ethylene succinate) blends containing Voriconazole, J. Drug Deliv. Sci. Technol. 46 (2018) 74-86.

[7] R. Ali, A. Dashevsky, R. Bodmeier, Poly vinyl acetate and ammonio methacrylate copolymer as unconventional polymer blends increase the mechanical robustness of HPMC matrix tablets, Int. J. Pharmaceut. 516 (2017) 3-8.

[8] J. D. N. Ogbonna, A. A. Attama, K. C. Ofokansi, S. B. Patil, G. D. Basarkar, Optimization of formulation processes using Design Expert ${ }^{\circledR}$ software for preparation of polymeric blends-artesunate-amodiaquine HCl microparticles, J. Drug Deliv. Sci. Technol. 39 (2017) $36-49$. 
[9] Z. Mirzaie, A. Reisi-Vanani, M. Barati, Polyvinyl alcohol-sodium alginate blend, composited with 3D-graphene oxide as a controlled release system for curcumin, J. Drug Deliv. Sci. Technol. 50 (2019) 380-387.

[10] A. Amarjargal, M. Brunelli, G. Fortunato, F. Spano, R. M. Rossi, On-demand drug release from tailored blended electrospun nanofibers, J. Drug Deliv. Sci. Technol. 52 (2019) 8-14.

[11] S. Ensslin, K. P. Moll, H. Metz, M. Otz, K. Mäder, Polymer blends for controlled release coatings, J. Control. Release 125 (2008) 1-15.

[12] Y. Cuppok, S. Muschert, M. Marucci, J. Hjaertstam, J. Siepmann, pH-independent release from coated pellets: Effect of coating composition on solubilization processes and drug release, Eur. J. Pharm. Biopharm. 72 (2009) 111-118.

[13] L. Ho, Y. Cuppok, S. Muschert, K. C. Gordon, M. Pepper, Y. C. Shen, YC, F. Siepmann, J. Siepmann, P. F. Taday, T. Rades, Effects of film coating thickness and drug layer uniformity on in vitro drug release from sustained-release coated pellets: A case study using terahertz pulsed imaging, Int. J. Pharmaceut. 382 (2009) 151-159.

[14] L. Ho, Y. Cuppok, S. Muschert, K. C. Gordon, T. Rades, Drug release mechanisms from Kollicoat SR:Eudragit NE coated pellets, Int. J. Pharmaceut. 409 (2011) 30-37.

[15] E. Villar López, A. Luzardo Álvarez, J. Blanco Méndez, F. J. Otero Espinar, Cellulosepolysaccharide film-coating of cyclodextrin based pellets for controlled drug release, J. Drug Deliv. Sci. Technol. 42 (2017) 273-283.

[16] R. T. Liggins, H. M. Burt, Paclitaxel-loaded poly(l-lactic acid) microspheres 3: blending low and high molecular weight polymers to control morphology and drug release, Int. J. Pharmaceut. 282 (2004) 61-71.

[17] Z-W. Ye, P. Rombout, J. P. Remon, C. Vervaet, G. Van den Mooter, Correlation between the permeability of metoprolol tartrate through plasticized isolated 
ethylcellulose/hydroxypropyl methylcellulose films and drug release from reservoir pellets, Eur. J. Pharm. Biopharm. 67 (2007) 485-490.

[18] Y. El-Malah, S. Nazzal, Novel use of Eudragit® NE 30D/Eudragit ${ }^{\circledR}$ L 30D-55 blends as functional coating materials in time-delayed drug release applications, Int. J. Pharmaceut. 357 (2008) 219-227.

[19] H. Kranz, S. Gutsche, Evaluation of the drug release patterns and long term stability of aqueous and organic coated pellets by using blends of enteric and gastrointestinal insoluble polymers, Int. J. Pharmaceut. 380 (2009) 112-119.

[20] R. Wulff, C. S. Leopold, Coatings from blends of Eudragit ${ }^{\circledR}$ RL and L55: A novel approach in pH-controlled drug release, Int. J. Pharmaceut. 476 (2014) 78-87.

[21] F Lecomte, J Siepmann, M Walther, R. J MacRae, R Bodmeier, Blends of enteric and GIT-insoluble polymers used for film coating: physicochemical characterization and drug release patterns, J. Control. Release 89 (2003) 457-471.

[22] F. Lecomte, J. Siepmann, M. W. Ross, J. Mac Rae, R. Bodmeier, Polymer blends used for the Coating of multiparticulates: Comparison of aqueous and organic coating techniques, Pharm. Res. 21 (2004) 882-890.

[23] F. Siepmann, J. Siepmann, M. Walther, R. J. MacRae, R. Bodmeier, Blends of aqueous polymer dispersions used for pellet coating: Importance of the particle size, J. Control. Release 105 (2005) 226-239.

[24] R. L. Cleek, K. C. Ting, S. G. Eskin, A. G. Mikos, Microparticles of poly(dl-lactic-coglycolic acid)/poly(ethylene glycol) blends for controlled drug delivery, J. Control. Release 48 (1997) 259-268.

[25] H. B. Ravivarapu, K. Burton, P. P. DeLuca, Polymer and microsphere blending to alter the release of a peptide from PLGA microspheres, Eur. J. Pharm. Biopharm. 50 (2000) 263-270. 
[26] J. Liu, S. Lin, L. Li, E. Liu, Release of theophylline from polymer blend hydrogels, Int. J. Pharmaceut. 298 (2005) 117-125.

[27] F. Zhang, F. Meng, J. Lubach, J. Koleng, N. A. Watson, Properties and mechanisms of drug release from matrix tablets containing poly(ethylene oxide) and poly(acrylic acid) as release retardants, Eur. J. Pharm. Biopharm. 105 (2016) 97-105.

[28] M. C. Hamoudi-Ben Yelles, V. Tran Tan, F. Danede, J. F. Willart, J. Siepmann, PLGA implants: How Poloxamer/PEO addition slows down or accelerates polymer degradation and drug release, J. Control. Release 253 (2017) 19-29.

[29] E. Verhoeven, T. R. M. De Beer, E. Schacht, G. Van den Mooter, J. P. Remon, C. Vervaet, Influence of polyethylene glycol/polyethylene oxide on the release characteristics of sustained-release ethylcellulose mini-matrices produced by hot-melt extrusion: in vitro and in vivo evaluations, Eur. J. Pharm. Biopharm. 72 (2009) 463-470.

[30] S. P. Lyu, R. Sparer, C. Hobot, K. Dang, Adjusting drug diffusivity using miscible polymer blends, J. Control. Release 102 (2005) 679-687.

[31] R. Semdé, K. Amighi, D. Pierre, M. J. Devleeschouwer, A. J. Moës, Leaching of pectin from mixed pectin/insoluble polymer films intended for colonic drug delivery, Int. J. Pharmaceut. 174 (1998) 233-241.

[32] L. F. Siew, A. W. Basit, J. M. Newton, The properties of amylose-ethylcellulose films cast from organic-based solvents as potential coatings for colonic drug delivery, Eur. J. Pharma. Sci. 11 (2000) 133-139.

[33] R. Semdé, K. Amighi, M. J. Devleeschouwer, A. J. Moës, Studies of pectin $\mathrm{HM} /$ Eudragit ${ }^{\circledR}$ RL/Eudragit ${ }^{\circledR}$ NE film-coating formulations intended for colonic drug delivery, Int. J. Pharmaceut. 197 (2000) 181-192. 
[34] L. F.Siew, S.M. Man, J. M. Newton, A. W. Basit, Amylose formulations for drug delivery to the colon: a comparison of two fermentation models to assess colonic targeting performance in vitro, Int. J. Pharmaceut. 273 (2004) 129-134.

[35] P. J. Wilson, A. W. Basit, Exploiting gastrointestinal bacteria to target drugs to the colon: An in vitro study using amylose coated tablets, Int. J. Pharmaceut. 300 (2005) 89-94.

[36] S. Rujivipat, R. Bodmeier, Improved drug delivery to the lower intestinal tract with tablets compression-coated with enteric/nonenteric polymer powder blends, Eur. J. Pharma. Biopharm. 76 (2010) 486-492.

[37] Y. Rosiaux, S. Muschert, R. Chokshi, B. Leclercq, J. Siepmann, Ethanol-resistant polymeric film coatings for controlled drug delivery, J. Control. Release 169 (2013) 1-9.

[38] Y. Rosiaux, C. Velghe, S. Muschert, R. Chokshi, J. Siepmann, Ethanol-resistant ethylcellulose/guar gum coatings - Importance of formulation parameters, Eur. J. Pharma. Biopharm. 85 (2013) 1250-1258.

[39] Y. Rosiaux, C. Velghe, S. Muschert, R. Chokshi, B. Leclercq, F. Siepmann, J. Siepmann, Mechanisms controlling theophylline release from ethanol-resistant coated pellets, Pharm. Res. 31 (2014) 731-741.

[40] J. Siepmann, F. Lecomte, R. Bodmeier, Diffusion-controlled drug delivery systems: calculation of the required composition to achieve desired release profiles, J. Control. Release 60 (1999) 379-389.

[41] M. M. Crowley, B. Schroeder, A. Fredersdorf, S. Obara, M. Talarico, S. Kucera, J. W. McGinity, Physicochemical properties and mechanism of drug release from ethyl cellulose matrix tablets prepared by direct compression and hot-melt extrusion. Int. J. Pharmaceut. 269 (2004) 509-522. 
[42] H. L. Lai, K. Pitt, D. Q. M. Craig, Characterisation of the thermal properties of ethylcellulose using differential scanning and quasi-isothermal calorimetric approaches. Int. J. Pharmaceut. 286 (2010) 178-184.

[43] J. Huang, R. J. Wigent, J. B. Schwartz. Drug-Polymer interaction and its significance on the physical stability of nifedipine amorphous dispersion in microparticles of an ammonio methacrylate copolymer and ethylcellulose binary blend. J. Pharma. Sci. 97 (2008) 251262.

[44] D. Mudgil, S. Barak, B.S. Khatkar. X-ray diffraction, IR spectroscopy and thermal characterization of partially hydrolyzed guar gum. Int. J. Biol. Macromol. 50 (2012) 10351039.

[45] Y. S. R. Krishnaiah, V. Satyanarayana, B. D. Kumar, R. S. Karthikeyan, In vitro drug release studies on guar gum-based colon targeted oral drug delivery systems of 5fluorouracil. Eur. J. Pharm. Sci. 16 (2002) 185-192.

[46] S. M. Al-Saidan, Y. S. Krishnaiah, V. Satyanarayana, G. S. Rao, In vitro and in vivo evaluation of guar gum-based matrix tablets of Rofecoxib for colonic drug delivery, Curr. Drug. Deliv. 2 (2005) 155-63.

[47] R. Kaur, M. Gulati, S. K. Singh, Role of synbiotics in polysaccharide assisted colon targeted microspheres of mesalamine for the treatment of ulcerative colitis, Int. J. Biol. Macromol. 95 (2017) 438-450. 


\section{Supplementary material}

Hot melt extruded polysaccharide blends for controlled drug delivery

Y. Benzine ${ }^{1}$, F. Siepmann ${ }^{1}$, C. Neut ${ }^{2}$, F. Danede ${ }^{3}$, J.F. Willart ${ }^{3}$, J. Siepmann ${ }^{1}$, Y. Karrout ${ }^{1}$

${ }^{1}$ Univ. Lille, Inserm, CHU Lille, U1008, F-59000 Lille, France

${ }^{2}$ Univ. Lille, Inserm, CHU Lille, U995- LIRIC, F-59000 Lille, France

${ }^{3}$ Univ. Lille, USTL UMET UMR CNRS 8207, F-59650 Villeneuve d'Ascq, France 
zone 4

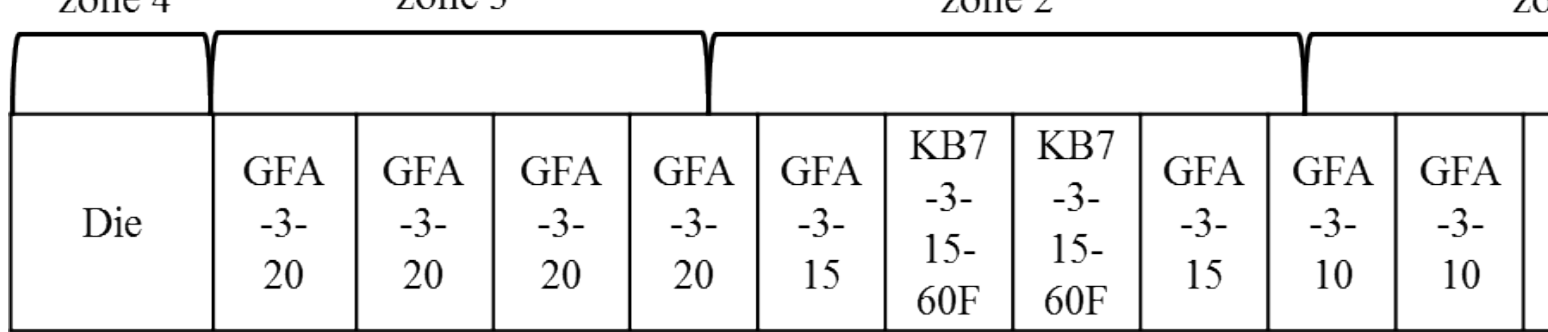

zone 1

\begin{tabular}{|c|c|c|c|c|c|l|}
\hline KB7 & KB7 & GFA & GFA & GFA & GFA & \\
$-3-$ & $-3-$ & $-3-$ & $-3-$ & $-3-$ & $-3-$ & Feeder \\
$15-$ & $15-$ & 20 & 20 & 15 & 10 & \\
$60 F$ & $60 F$ & & & & & \\
\hline
\end{tabular}

Figure S1: Setting of the screw elements used for hot melt extrusion. 


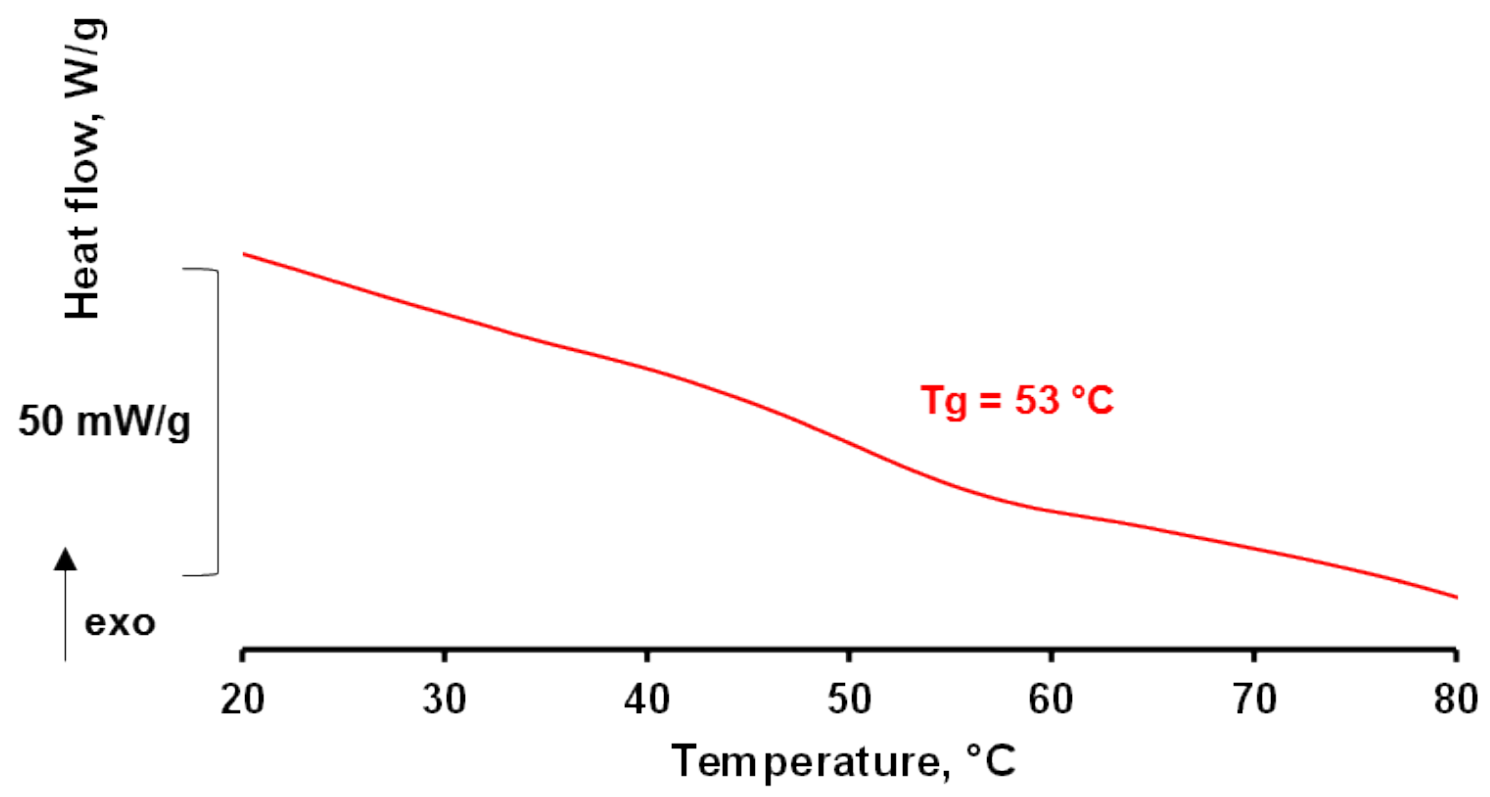

Figure S2: DSC thermogram of ethylcellulose plasticized with $30 \%$ DBS. 


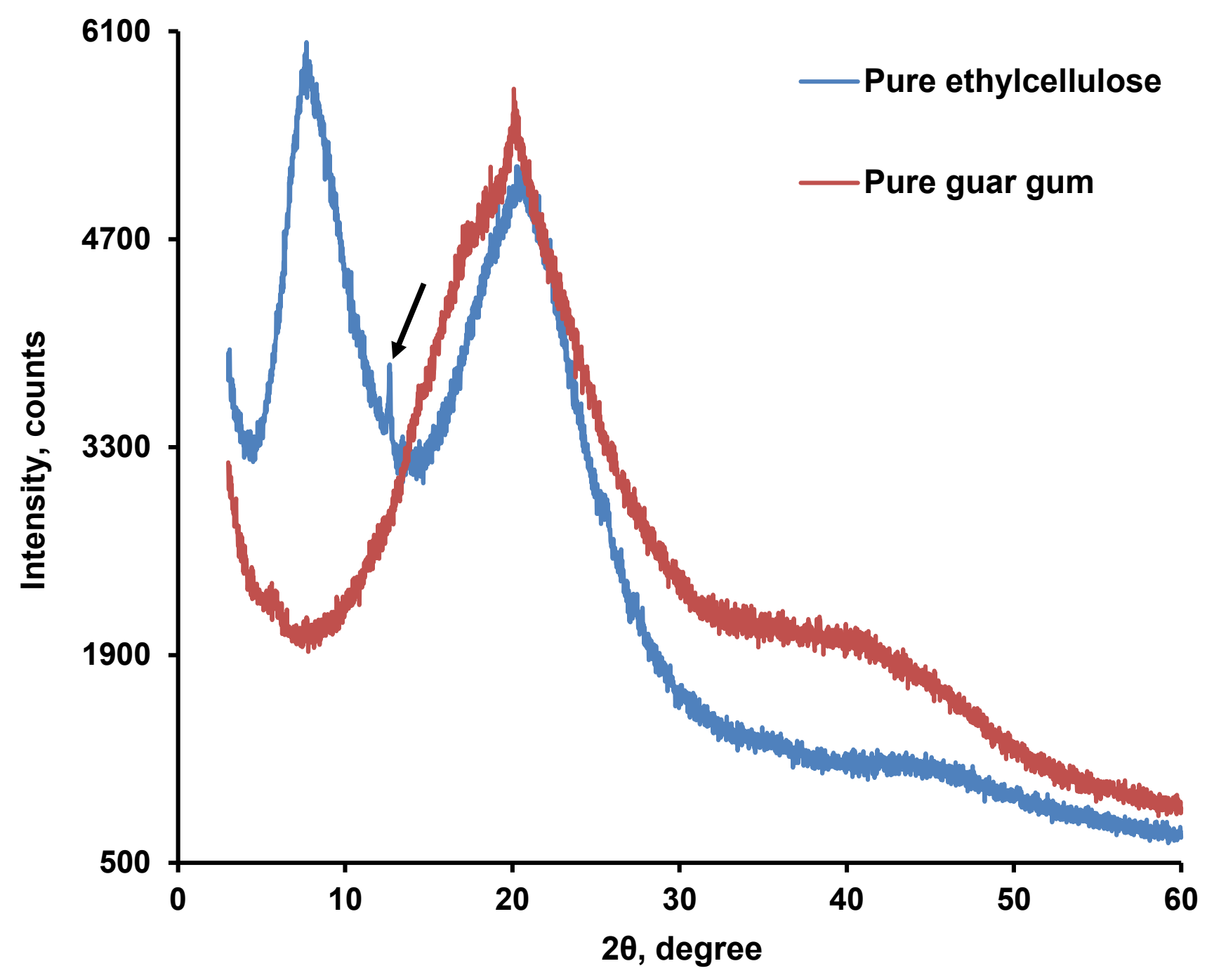

Figure S3: X-ray diffractograms of pure ethylcellulose and pure guar gum powders (as received). 


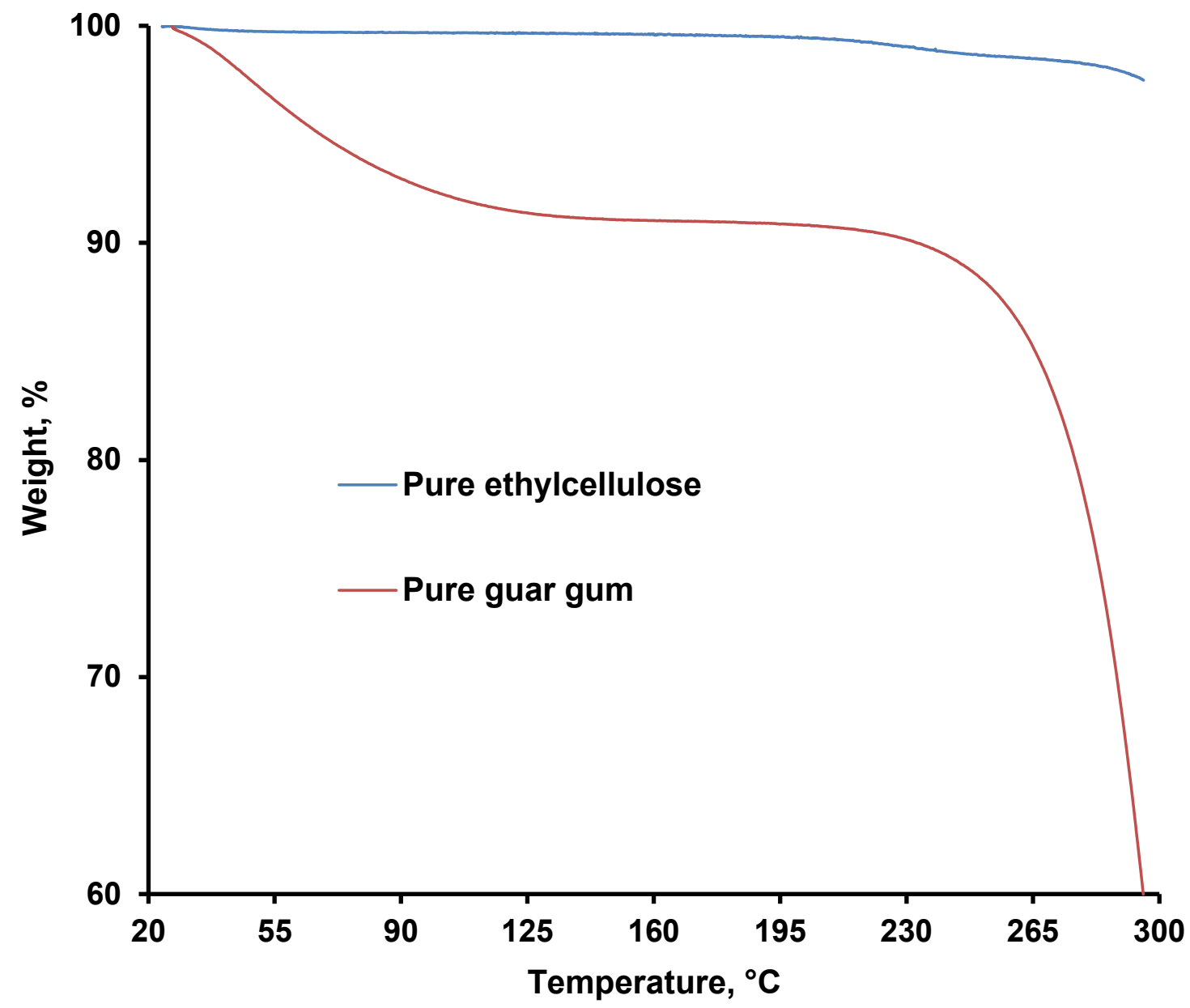

Figure S4: TGA thermograms of pure ethylcellulose and pure guar gum powders (as received). 
(80:20) Ethylcellulose:Guar gum

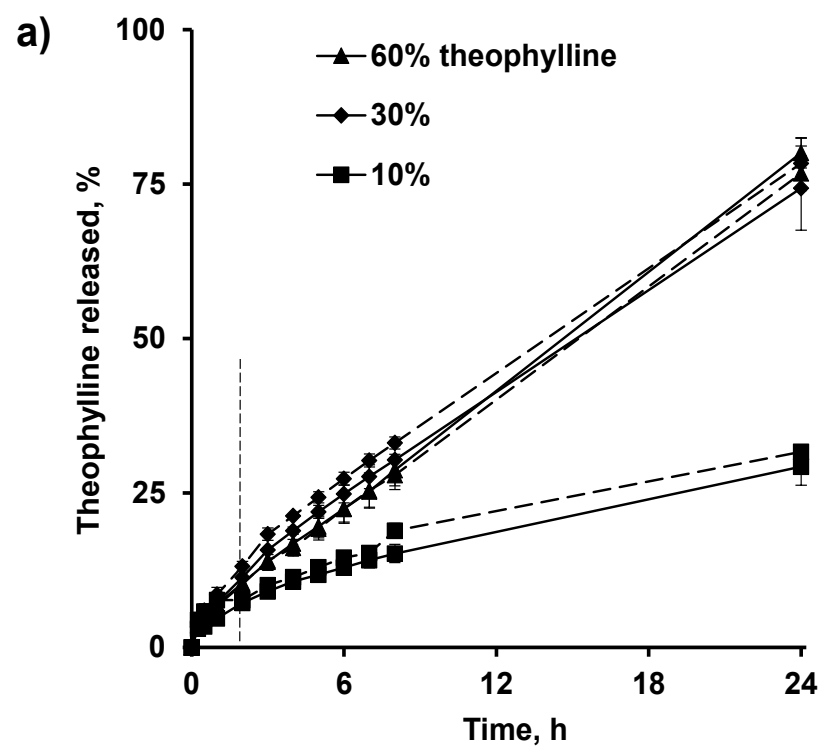

$(80: 20)$ Ethylcellulose:Guar gum

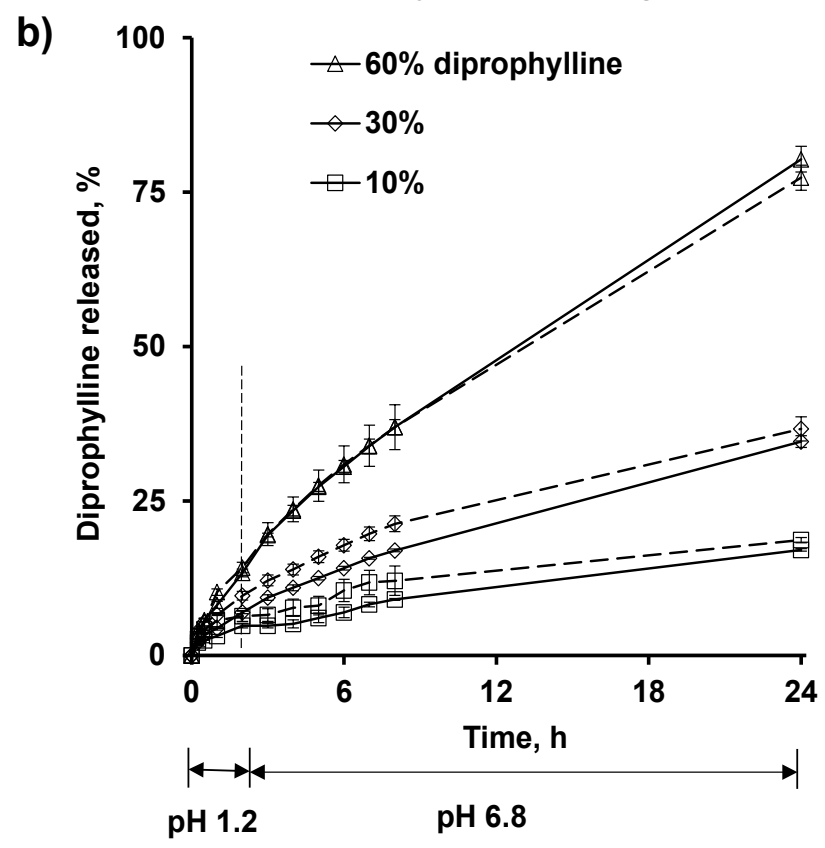

Figure S5: Storage stability of hot melt extrudates based on 80:20 ethylcellulose:guar gum blends loaded with: a) theophylline, or b) diprophylline. The extrusion temperature was $100{ }^{\circ} \mathrm{C}$, the extrudates were plasticized with $30 \%$ DBS. Drug release was measured in $0.1 \mathrm{M}$ $\mathrm{HCl}$ (for $2 \mathrm{~h}$ ), followed by phosphate buffer $\mathrm{pH} 6.8$ before (solid curves) and after 1- year open storage at ambient conditions (dotted curves). 